\title{
Multi-temporal LCZ maps for Canadian functional urban areas
}

\author{
Demuzere, M. ${ }^{12^{*}}$, Mihara, T. ${ }^{3}$, Redivo, C. P. ${ }^{3}$, Feddema, J. ${ }^{4}$, Setton, E. ${ }^{3}$
}

1. Kode VOF, Ghent (Belgium)

2. Department of Geography, Ruhr-University Bochum (Germany)

3. Canadian Urban Environmental Health Research Consortium (Canada)

4. University of Victoria, Victoria, BC, Canada

*Corresponding author: matthias@b-kode.be

Keywords: Local climate zones, Google Earth Engine, multi-temporal land cover, Canada, Landsat

\section{Introduction}

Land cover has been designated by the Global Climate Observing System (GCOS) as an Essential Climate Variable due to its integral role in many climate and environmental processes (Arevalo et al., 2020). In this context, urban areas today still represent only a small proportion of the Earth's land surface, yet since they are characterised by high population densities, they are extremely sensitive and vulnerable to weather/air quality/climate variations inducing/enhancing health impacts and affecting economic activities (Baklanov, et al., 2018). Successful mitigation and adaptation to climate change will depend centrally on what happens in cities (Grimm et al., 2008). Yet despite this focus on cities as a critical scale for climate change management, we know very little about most cities on the planet (Creutzig et al., 2019; Demuzere et al., 2020a). The right data at the right scale are an essential prerequisite for developing fit-for-purpose urban planning policies (Georgescu et al., 2015). In addition, identifying the evolution of urban systems in time and space is crucial towards sustainable urban development (Lemoine-Rodríguez et al., 2020).

Efforts that continue to monitor urban growth dynamics are therefore essential, and should not be limited to binary products (so-called "urban masks", Bechtel et al., 2017). In recent years, the global urban extent and urban growth has been mapped at finer and finer detail (e.g. Pesaresi et al., 2013; Esch et al., 2017; Gong et al., 2020), but these efforts need to be complemented by a wider range of information-rich intra-urban classes that describe different types of urban land covers and land uses (Demuzere et al., 2020a; Lemoine-Rodríguez et al., 2020). The Local Climate Zone (LCZ) typology is a good example of such classification scheme (Stewart and Oke, 2012; Ching et al., 2018; Reba and Seto, 2020), providing a landscape approach that can distinguish urban surfaces on a holistic basis, accounting for the typical combination of micro-scale land-covers and associated physical properties (Demuzere et al., 2020a). 
The LCZ typology consists out of seventeen types (10 of which are considered urban, Figure 1) that are formally defined as "regions of uniform surface cover, structure, material, and human activity that span hundreds of meters to several kilometers in horizontal scale", exclude "class names and definitions that are culture or region specific", and are characterized by "a characteristic screen-height temperature regime that is most apparent over dry surfaces, on calm, clear nights, and in areas of simple relief" (Stewart and Oke, 2012). Because of its universality, the LCZ scheme has been adopted by the World Urban Database and Access Portal Tools (WUDAPT, www.wudapt.org) community project as a baseline description of cities, thereby providing both a common platform for knowledge exchange and a pathway to model applications in cities where there is little data infrastructure (Ching et al., 2018).

Over the past decade, the interest in LCZs has been growing steadily, reflected by the growing number of scientific publications having 'LCZ' or 'Local Climate Zones' listed as keywords: according to Web of Science, as of November 27 2020, a total of 129 papers were published, 38 of them in 2020 alone (Demuzere et al., under review). Yet to date, to the best of our knowledge, only two scientific papers attempted to produce multi-temporal LCZ maps: Vandamme et al. (2019) and Wang et al. (2019), for respectively the city of Kunming and the Pearl River Delta (both in China).

This work contributes to this effort, by developing multi-temporal LCZ maps for a selection of seven Canadian functional urban areas, covering the last seven census years $(1986,1991,1996,2001,2006,2011,2016)$. Results of this work will be incorporated into the Canadian Urban Environmental Health Research Consortium (CANUE, https://canue.ca/) data holdings, to be distributed to researchers interested in studying links between urban form and a wide range of health outcomes. 


\section{Built types}
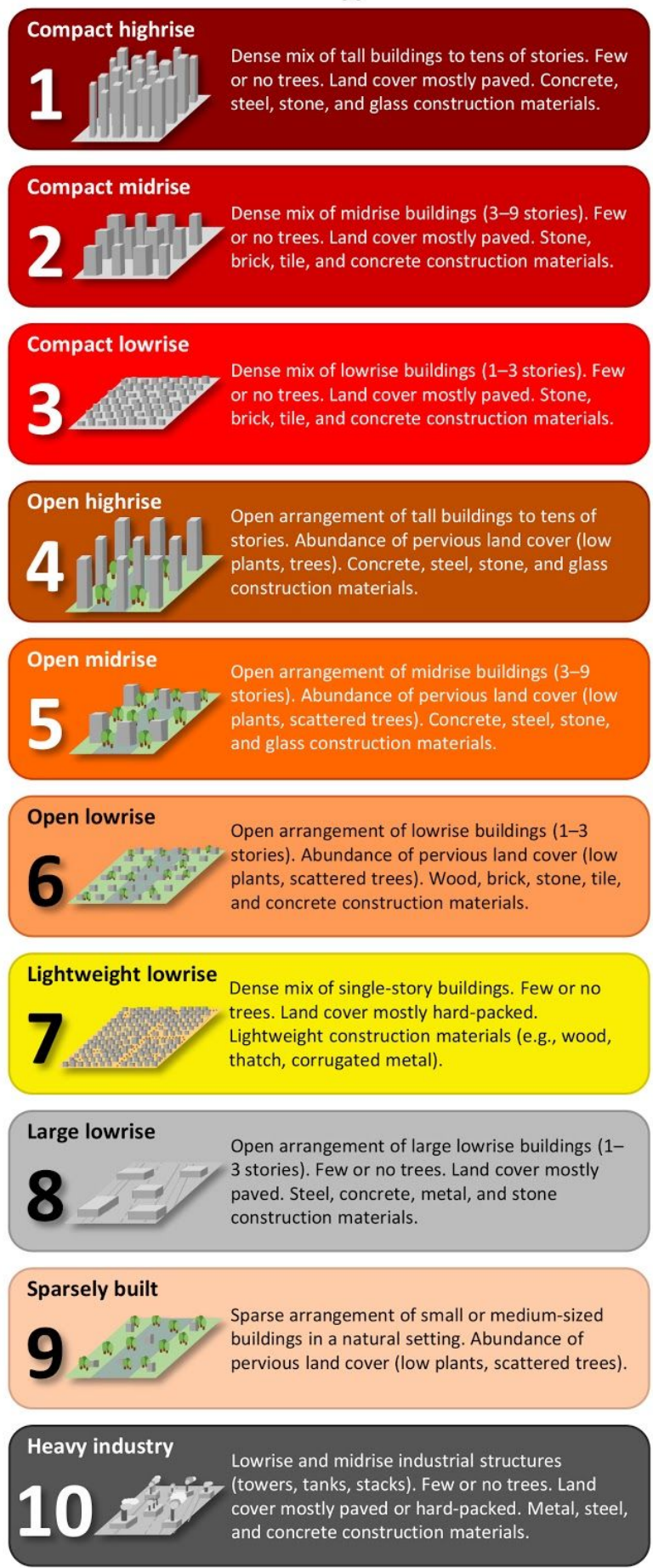

\section{Land cover types}
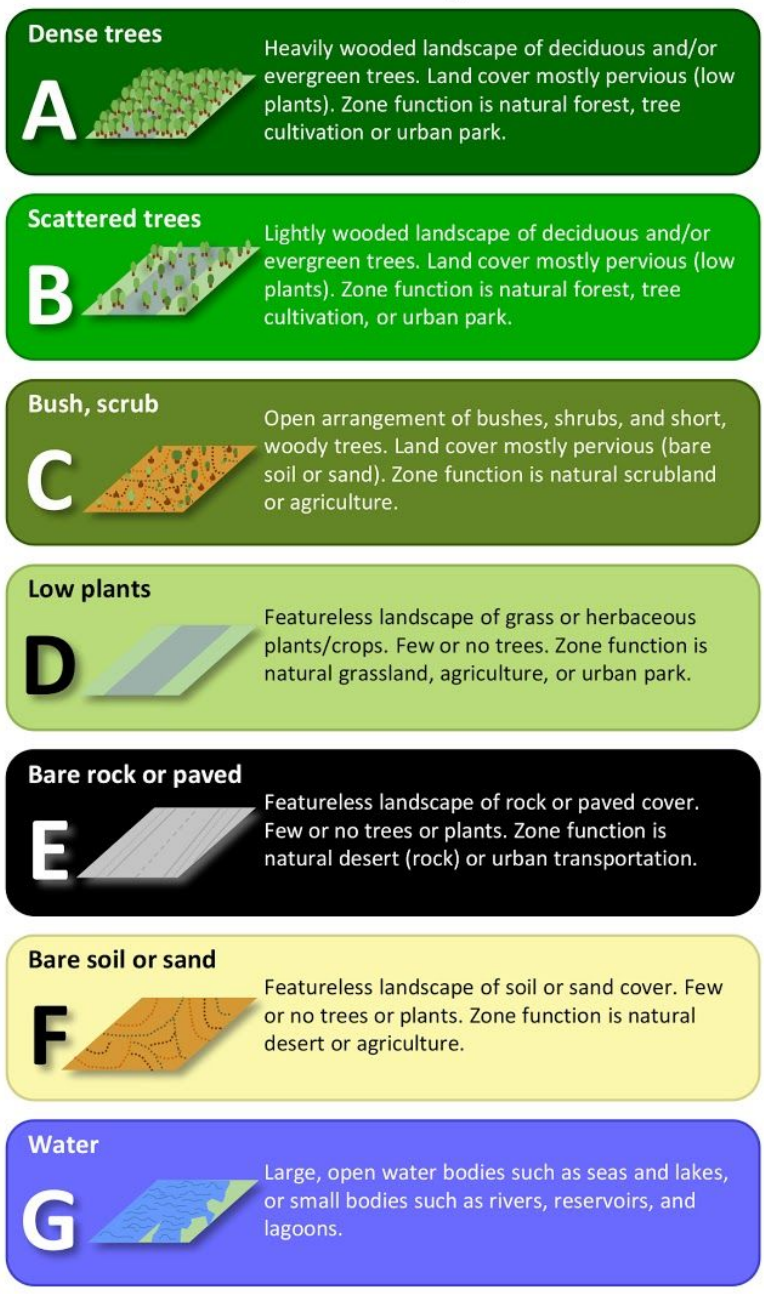

\section{VARIABLE LAND COVER PROPERTIES}

Variable or ephemeral land cover properties that change significantly with synoptic weather patterns, agricultural practices, and/or seasonal cycles.

\begin{abstract}
b. bare trees Leafless deciduous trees (e.g., winter). Increased sky view factor. Reduced albedo.
\end{abstract}
s. snow cover Snow cover $>10 \mathrm{~cm}$ in depth. Low admittance. High albedo.
d. dry ground Parched soil. Low admittance. Large Bowen ratio. Increased albedo.
w. wet ground Waterlogged soil. High admittance. Small Bowen ratio. Reduced albedo.

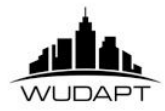

Figure 1: Urban (1-10) and natural $(A-G)$ Local Climate Zone definitions (Demuzere et al., 2020a). 


\section{Methods}

The procedure to create dynamic, multi-temporal Local Climate Zone maps is not much different from the static LCZ mapping procedure: one still needs labeled training areas (TAs), earth observation input features and a classification algorithm (Bechtel et al., 2015; Vandamme et al., 2019). Yet of course, dynamic LCZ mapping implies two major constraints: 1) the TAs should be representative of the periods considered, and 2) the earth observation input features should be available across these periods.

\subsection{Training areas and region of interest}

TAs are carefully selected to be representative for all census years, and are derived by local urban experts using Google Earth and the Google Earth Engine timelapse tool (https://earthengine.google.com/timelapse/) to find areas that have remained in the same LCZ class over time. The seven urban areas of interest are Calgary, Edmonton, Halifax, Montreal, Toronto, Vancouver and Winnipeg. Their urban extent is obtained by taking the bounding box of each of their functional urban areas (FUAs), as defined by Schiavina et al. (2019; data available here). A total of 1054 TAs are digitized across these functional urban areas, with their LCZ class count distribution per city shown in Figure 2. 


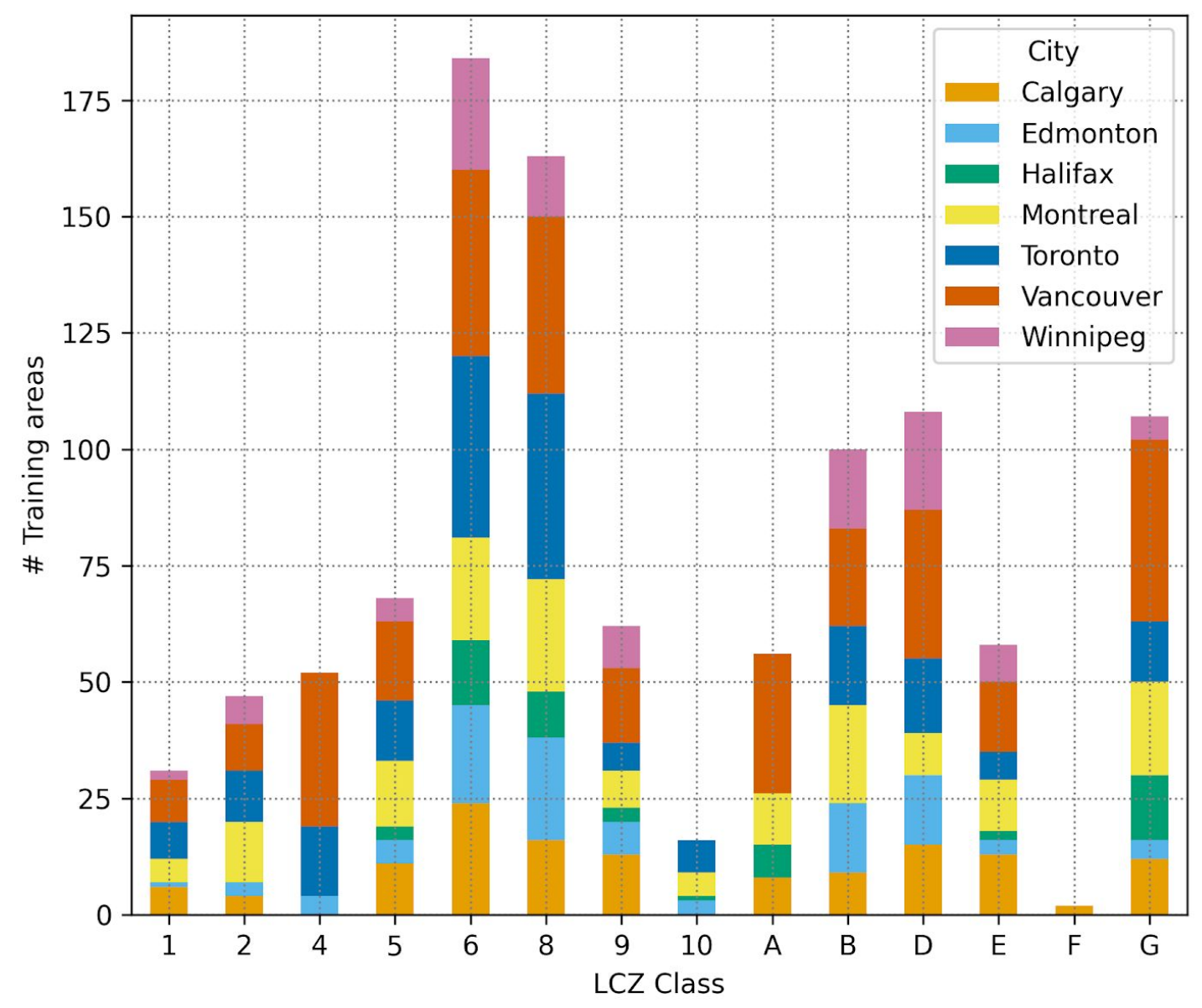

Figure 2: Number of training areas per city and LCZ class.

\subsection{Earth observation input features}

Because Sentinel 1 / 2 imagery previously used by Demuzere et al. (2019a,b; 2020a) are not available prior to 2014 / 2015 respectively, only Landsat-based input features are used. Input features from Landsat 5, 7 (years prior to 2003 because of the scan line error) and 8 are selected according to the input feature importance ranking from Demuzere et al. (2019b), and include information from all common wavelengths (blue, green, red, near infrared (nir), shortwave infrared (swir) 1/2 and thermal infrared (tirs) 1) and a number of band ratios: minimum and maximum Normalized Difference Vegetation Index (NDVI), the Biophysical Composition Index (BCl; Deng and Wu, 2012) using the Tasseled Cap transformation coefficients from Devries et al. (2016), the Normalized Difference BAreness Index (NDBAl; Li et al., 2017), the mean Normalized Difference 
Water Index (NDWl; Ko et al., 2015), and the Normalized Difference Urban Index (NDUl; Zhang et al., 2015).

All input features are derived for the census year \pm 1 year, and for the months May to October (Julian days 120 to 240), in order to avoid snow cover. Except for the minimum and maximum NDVI and maximum NDWI, all other bands reflect a median composite, and are processed on a resolution of $100 \mathrm{~m}$, following the default mapping resolution suggested by Bechtel et al. (2015).

\subsection{Classification procedure, accuracy assessment, and post-processing}

The classification procedure in this study follows the Google earth engine LCZ classification approach developed by Demuzere et al. (2019a,b; 2020a), and is repeated seven times (for each census year of interest), because of the differences between the Landsat sensors (see e.g. Mancino et al., 2020). For each census year, the classifier is trained and tested using all TAs, and all earth observation input features from that year. The classification is then repeated 25 times in a bootstrapping manner, each time randomly (stratified) selecting 70 and $30 \%$ of all available TAs for training and testing respectively.

The accuracy assessment is done using the following metrics: overall accuracy (OA), overall accuracy for the urban LCZ classes only $\left(\mathrm{OA}_{\mathrm{u}}\right)$, overall accuracy of the built versus natural LCZ classes only $\left(O A_{b u}\right)$, a weighted accuracy $\left(O A_{w}\right)$, and the class-wise metric F1. The assessment is done for each bootstrapping iteration, allowing us to provide confidence intervals around the accuracy metrics. Please see Demuzere et al. (2020a) and references therein for more information.

Finally, the resulting LCZ map is produced using all available TAs and input features, per census year, and per functional urban area, and is filtered using the morphological Gaussian filter developed by Demuzere et al. (2020a).

\section{Results}

Overall accuracies $\left(\mathrm{OA}, \mathrm{OA}_{\mathrm{u}}, \mathrm{OA}_{\mathrm{bu}}, \mathrm{OA}_{\mathrm{w}}\right)$ across FUA's and census years are high, ranging between 0.66 and 0.99 (e.g. Figure 3 for Montreal). Class-specific F1 scores are more variable, with accuracies ranging between $\sim 0.2$ and 1.0. Highest accuracies are typically obtained for most natural classes and LCZs 6 and 8; lower accuracies for e.g. LCZ 4 (open high-rise) and LCZ 5 (open mid-rise). These classes appear at low frequencies in Canadian cities, so they lack abundant training data. In addition, in line with previous findings, we hypothesise that the confusion of urban classes is also 
caused by limitations of the input feature space that is currently not able to detect height variations (see e.g. Vandamme et al. (2019) and Demuzere et al. (2019b, 2020a)).
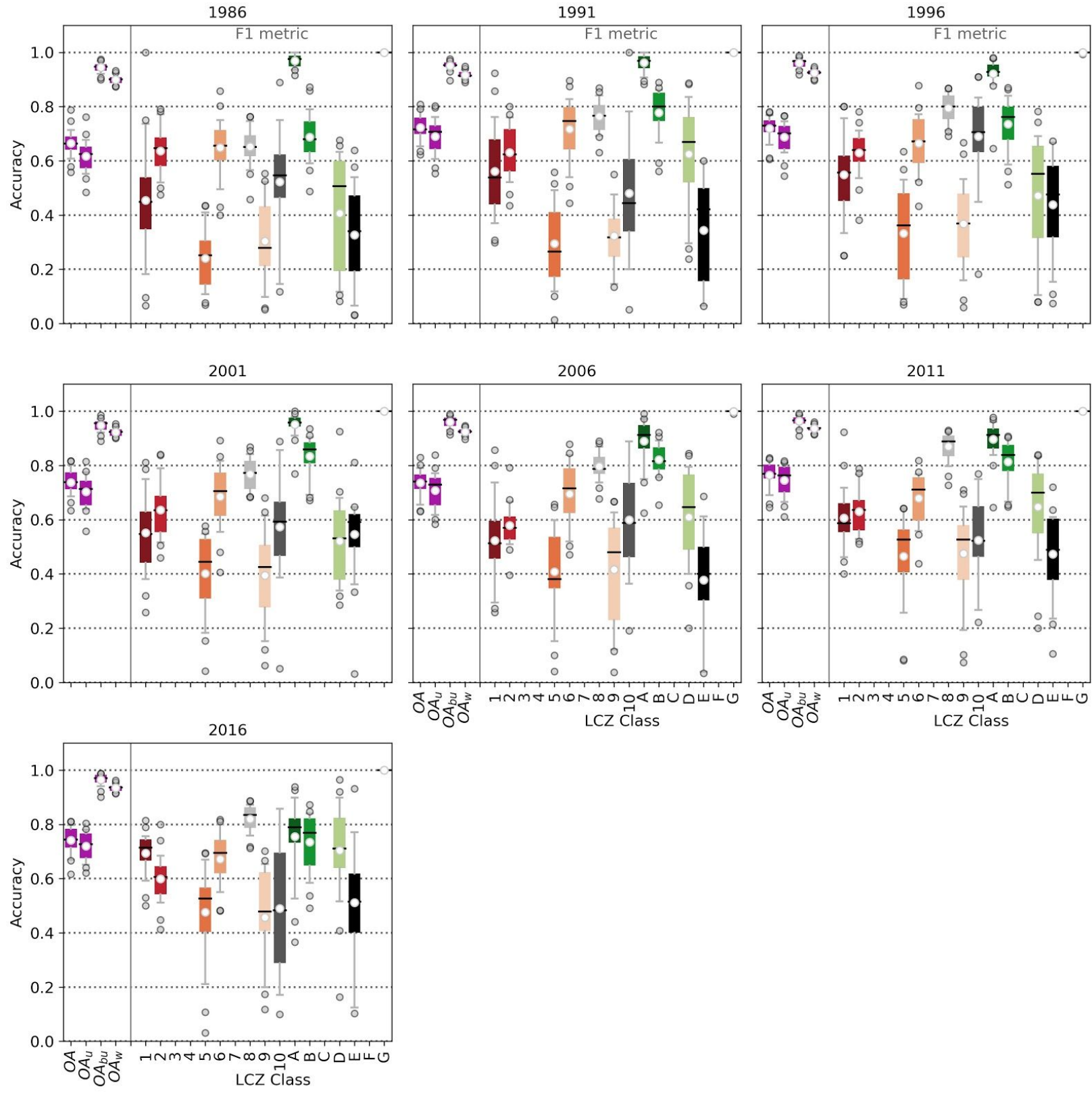

Figure 3: Overall and class-wise accuracies per year for Montreal. Colored boxes and grey whiskers span the 25-75 and 5-95 percentiles respectively. The means and medians are indicated by the white dots and black lines respectively. The purple boxes represent the overall accuracy metrics, the LCZ-colored boxes the F1 class-wise accuracy metric. Results for other cities are provided in Figures S1-S6.

Low values for LCZ 9 (sparsely built) probably originate from the fact that this class is dominated by natural land cover, and is easily confused with one of the natural LCZ types. Because of this behaviour, and the fact that this LCZ class in turn behaves 
thermally as a natural land-cover, LCZ 9 was recently not considered in Demuzere et al. (2020a). Yet overall, all metrics and LCZ-class specific accuracies and differences are generally stable across census years, indicating that the LCZ maps are robust across time, even though they are a product of different underlying Landsat sensor composites.

The multi-temporal LCZ maps for Montreal are shown in Figure 4 (and in the Supplementary Information for all other cities). In general, most cities indicate urban growth between 1986 and 2016, even though the trend is not consistent and necessarily linear (Table 1).
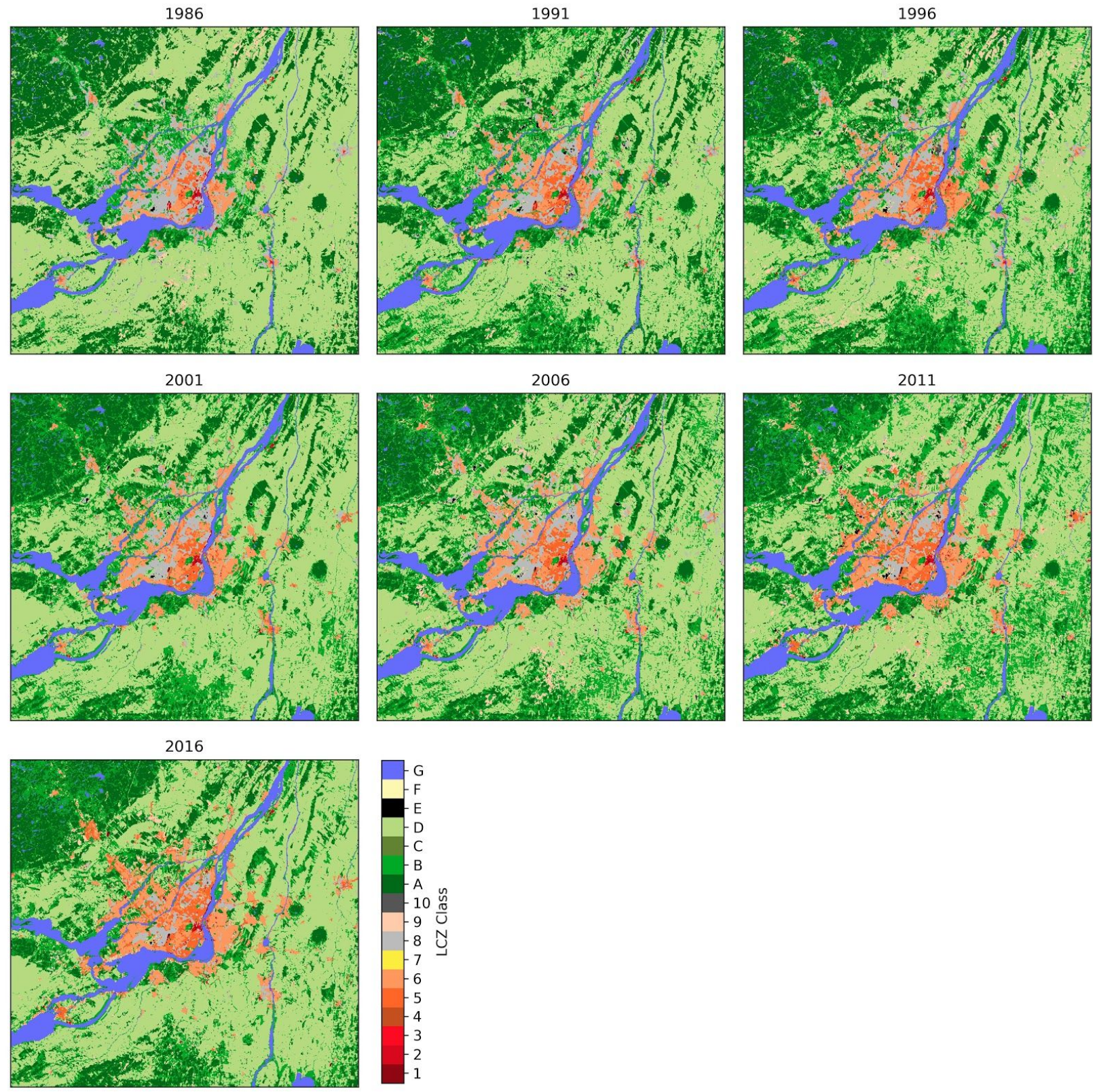

Figure 4: LCZ map per census year, for Montreal. Results for other cities are provided in

Figures S7-S12. 
For example, Edmonton reached its peak urban extent in $1996\left(\sim 1500 \mathrm{~km}^{2}\right)$, yet currently only has an urban extent of $1246 \mathrm{~km}^{2}$. A more detailed (metadata) analysis is needed to understand whether this is reality, or rather an artefact of the classifier's confusion. For some cities (e.g. Toronto and Calgary), the first census year 1986 seems to indicate a much higher urban extent compared to more recent census years. This might point to a different quality of the input features across time, or to the fact that even though the TAs were digitized with great care - they do not necessarily reflect historical conditions.

Table 1: Approximate total urban surface area $\left(\mathrm{km}^{2}\right)$ for each FUA and census year. Because of the confusion in LCZ 9 and its predominant natural character, this class is not taken into account here, so only LCZs $1-8$ and 10 are counted as "urban".

\begin{tabular}{l|ccccccc}
\hline & $\mathbf{1 9 8 6}$ & $\mathbf{1 9 9 1}$ & $\mathbf{1 9 9 6}$ & $\mathbf{2 0 0 1}$ & $\mathbf{2 0 0 6}$ & $\mathbf{2 0 1 1}$ & $\mathbf{2 0 1 6}$ \\
\hline Calgary & 993.7 & 894.0 & 1027.8 & 827.8 & 847.2 & 919.0 & 1034.2 \\
Edmonton & 1178.7 & 1162.2 & 1493.6 & 1274.4 & 1073.3 & 1026.8 & 1246.0 \\
Halifax & 178.1 & 179.8 & 193.5 & 206.7 & 204.6 & $183.4^{*}$ & 248.6 \\
Montreal & 1514.3 & 1465.9 & 1531.6 & 1519.6 & 1811.2 & 1654.1 & 1781.2 \\
Toronto & 4516.9 & 3572.9 & 3242.8 & 3545.8 & 3521.7 & 3456.5 & 3493.2 \\
Vancouver & 1131.1 & 1056.6 & 1047.5 & 1012.6 & 1031.6 & 1037.8 & 1085.7 \\
Winnipeg & 375.4 & 390.6 & 454.6 & 439.6 & 513.9 & 451.4 & 511.4 \\
*A large part of this $L C Z$ map is missing due to cloud cover. See also Fig S8. &
\end{tabular}

The change of the LCZ class frequencies over time is also visualised as the ratio against the total number of LCZs and urban LCZs, as shown in Figure $\mathbf{5}$ for Montreal. While the amount of LCZ classes 1 (compact highrise) and 2 (compact midrise) are relatively stable, there is a strong increase in LCZs 5 (open midrise) and 6 (open lowrise), and a decrease in LCZ 8 (large lowrise). This is balanced by a decrease in LCZs A (dense trees) and D (low plants), and an increase in LCZ B (scattered trees). Please refer to Figures $\mathbf{S 1 3}$ to $\mathbf{S} 18$ to assess LCZ class frequency changes for all other cities. 

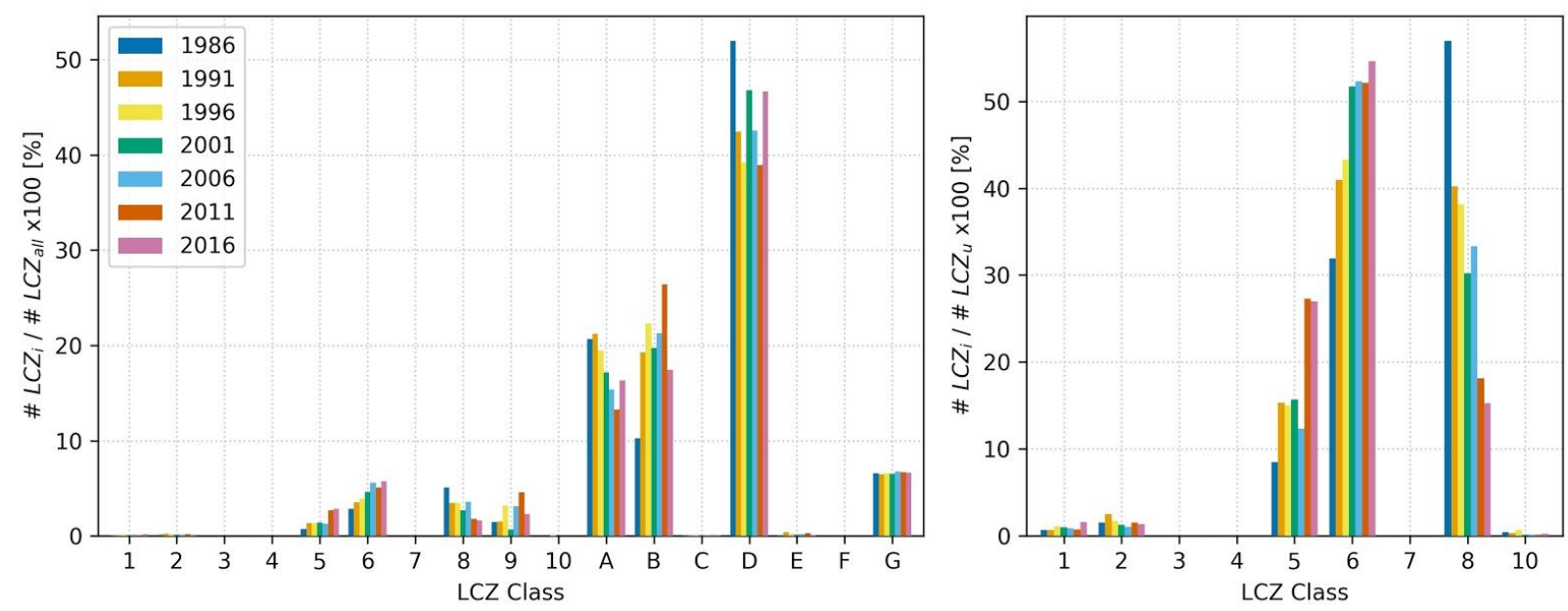

Figure 5: Share of each LCZ type $i$ in Montreal, as the percentage of (left) the total number of LCZs and (right) the total number of urban LCZs (1-8 and 10). Please see Supplementary

Figures S13-S18 for the other cities.

\section{Discussion and conclusion}

This study explores the multi-temporal Local Climate Zone mapping of large functional urban areas in Canada, for seven census years between 1986-2016. While this has been done before by others (Vandamme et al., 2019; Wang et al., 2019), none of these studies go back that far in time, nor apply the approach on as many urban functional areas and intermediate years.

The results are overall of good quality, indicated by the sufficiently high overall accuries. Yet the class-wise F1 metric does reveal extensive confusion between some of the urban LCZ classes. This is due to the similarity of the spectral reflectance characteristics between the built zones, and the fact that distinctions between high-, mid- rise, and low-rise classes are difficult to make. Such confusion between LCZs 1-6 is a common issue (Vandamme et al., 2019; Demuzere et al., 2019a, b; 2020a) due to the lack of building height information in Landsat bands. Improving this deficiency is not only a challenge for static present-day LCZ mapping efforts, but might prove even more challenging for historical, multi-temporal classification efforts.

Training areas of high quality are key for an optimal LCZ classification performance (Ching et al., 2018). Especially since large discrepancies were observed between LCZ maps, when TAs are selected by different individuals in a crowd-sourced experiment (Bechtel et al., 2017; Verdonck et al., 2019). In a multi-temporal LCZ mapping context, this challenge is aggravated, since training areas should be meticulously chosen to be valid and static across all census years. This is currently done using Google Earth 
Engine's timelapse tool as a visual reference when digitizing training areas in Google Earth, yet often historical images are of low quality or not available for the year of interest. Future work could therefore focus on a different strategy: instead of investing time in the digitization of training areas valid across time, it might be more opportune to focus more on harmonizing the Landsat information across sensors, using temporal segmentation approaches. LandTrendr (Kennedy et al., 2018) or the Continuous Change Detection and Classification algorithm (Arevalo et al., 2020) could be good candidates, as both have recently been made publicly accessible via Google's earth engine. Combining such strategies with the LCZ mapping procedure might allow one to train the LCZ classifier using present-day training areas only, combined with all available input features, presumably leading to a much more robust LCZ classification. Such a strategy could inherently also provide the classifier with the much needed seasonal information/variability (e.g. Demuzere et al., 2019a,b; 2020a), considering that different years might be subject to different climatic conditions. Such information was not available in the current study, as only summer images were used due to snow cover in Canadian winters.

As Creutzig et al. (2019) put it: "data-based approaches that expand our knowledge on global urban areas have the potential to upscale urban climate solutions and effect change at the global scale". The recent developments of continental-wide LCZ maps (Demuzere et al., 2019b,c; 2020a,b), or the LCZ Generator (Demuzere et al., under review) - an online, cloud-based tool to map any global city into Local Climate Zones - is a good step forward. Yet more work is required that addresses historical dynamics in urban form and morphology, allowing us to improve our understanding of the relation between a changing intra-urban environment and its environmental impacts. Such information is key in order to enable the building of future resilient, thriving, and sustainable cities.

\section{Supplementary information}

Figures in this report display results for Montreal only. Please see supplementary information below for the figures for all other cities.

\section{Data records \& Usage Notes}

All multi-temporal LCZ maps for all functional areas and census years are provided on a $100 \mathrm{~m}$ spatial resolution on a regular geographic coordinate system (EPSG:4326). All original training areas are combined in one shapefile, in the same projection. Both datasets are available via figshare (Demuzere et al., 2020c). All earth observation input features derived from Landsats 5,7 and 8 are freely available, and are computed on and stored as assets in Google Earth Engine (Gorelick et al., 2017). 
Local Climate Zones were originally designed as a new framework for urban heat island studies, and therefore contain "natural" land-cover classes that can be used as "control" or "natural reference" areas (Stewart and Oke, 2012). Yet the very few natural classes in the LCZ scheme can not capture the world's existing natural variability, and can thus with respect to the natural land-cover classes - not compete with other products such as the 20 and 36 layers that describe the Earth's terrestrial surface in the Copernicus Global Land-Cover Layers (Buchhorn et al., 2020) and the European Space Agency Climate Change Initiative land-cover (ESA, 2017) products respectively. In contrast, the strongest added value of the LCZ framework (and map) is the high number of urban classes, adding value to other, often binary, global urban products (e.g. the Global Human Settlement Layer (GHSL, Pesaresi et al., 2013), the Global Urban Footprint (GUF, Esch et al., 2017), and the Global Artificial Impervious Areas (GAIA, Gong et al., 2020)). We therefore advise users to combine the urban LCZ classes with any other land-cover product that provides a wider range of natural land-cover classes.

\section{Acknowledgements}

We thank USGS and NASA for the free Landsat data and the National Centers for Environmental Information at the National Oceanic and Atmospheric Administration (NOAA) for the DMSP-OLS data, all acquired via Google Earth Engine. Funding for this study was provided by the Canadian Urban Environmental Health Research Consortium (CANUE).

\section{References}

Arévalo, P., Bullock, E. L., Woodcock, C. E., \& Olofsson, P. (2020). A Suite of Tools for Continuous Land Change Monitoring in Google Earth Engine. Frontiers in Climate, 2(December), 1-19. https://doi.org/10.3389/fclim.2020.576740

Baklanov, A., Grimmond, C. S. B., Carlson, D., Terblanche, D., Tang, X., Bouchet, V., ... Hovsepyan, A. (2018). From urban meteorology, climate and environment research to integrated city services. Urban Climate, 23, 330-341. https://doi.org/10.1016/j.uclim.2017.05.004

Bechtel, B., Alexander, P., Böhner, J., Ching, J., Conrad, O., Feddema, J., ... Stewart, I. (2015). Mapping Local Climate Zones for a Worldwide Database of the Form and Function of Cities. ISPRS International Journal of Geo-Information, 4(1), 199-219. https://doi.org/10.3390/ijgi4010199

Bechtel, B., Demuzere, M., Sismanidis, P., Fenner, D., Brousse, O., Beck, C., ... Verdonck, M.-L. (2017). Quality of Crowdsourced Data on Urban Morphology-The Human Influence Experiment (HUMINEX). Urban Science, 1(2), 15. https://doi.org/10.3390/urbansci1020015 
Buchhorn, M. et al. (2020). Copernicus global land cover layers-collection 2. Remote. Sens. 12, 1-14, https://doi.org/10.3390/rs12061044.

Ching, J., Mills, G., Bechtel, B., See, L., Feddema, J., Wang, X., ... Theeuwes, N. (2018). WUDAPT: An Urban Weather, Climate, and Environmental Modeling Infrastructure for the Anthropocene. Bulletin of the American Meteorological Society, 99(9), 1907-1924. https://doi.org/10.1175/BAMS-D-16-0236.1

Cohen, W. B., Yang, Z., Healey, S. P., Kennedy, R. E., \& Gorelick, N. (2018). A LandTrendr multispectral ensemble for forest disturbance detection. Remote Sensing of Environment, 205(November 2017), 131-140. https://doi.org/10.1016/j.rse.2017.11.015

Creutzig, F., Lohrey, S., Bai, X., Baklanov, A., Dawson, R., Dhakal, S., ... Walsh, B. (2019). Upscaling urban data science for global climate solutions. Global Sustainability, 2, e2. https://doi.org/10.1017/sus.2018.16

Demuzere, M., Bechtel, B., \& Mills, G. (2019a). Global transferability of local climate zone models. Urban Climate, 27, 46-63. https://doi.org/10.1016/j.uclim.2018.11.001

Demuzere, M., Bechtel, B., Middel, A., \& Mills, G. (2019b). Mapping Europe into local climate zones. PLOS ONE, 14(4), e0214474. https://doi.org/10.1371/journal.pone.0214474

Demuzere, M., Bechtel, B., Middel, A., \& Mills, G. (2019c). European LCZ map. Figshare. https://doi.org/10.6084/m9.figshare.13322450.v1

Demuzere, M., Hankey, S., Mills, G., Zhang, W., Lu, T., \& Bechtel, B. (2020a). Combining expert and crowd-sourced training data to map urban form and functions for the continental US. Scientific Data, 7(1), 264. https://doi.org/10.1038/s41597-020-00605-z

Demuzere, M., Hankey, S., Mills, G., Zhang, W., Lu, T., \& Bechtel, B. (2020b). CONUS-WIDE LCZ map and Training Areas. Figshare. https://doi.org/10.6084/m9.figshare.11416950

Demuzere, M., Kittner, J., \& Bechtel, B. (under review). LCZ Generator: online tool to create Local Climate Zone maps. Frontiers in Environmental Science.

Demuzere, M., Mihara, T, Redivo, C., Feddema, J., Setton, E. (2020c). Multi-temporal LCZ maps for Canadian functional urban areas. Figshare. https://doi.org/10.6084/m9.figshare.13387082

Deng C, Wu C. (2012). BCl: A biophysical composition index for remote sensing of urban environments. Remote Sensing of Environment, 127:247-259. https://doi.org/10.1016/j.rse.2012.09.009 
Devries, B., Pratihast, A. K., Verbesselt, J., Kooistra, L., \& Herold, M. (2016). Characterizing forest change using community-based monitoring data and landsat time series. PLoS ONE, 11(3), 1-25. https://doi.org/10.1371/journal.pone.0147121

ESA. Land Cover CCI Product User Guide Version 2.0. Tech. Rep., European Space Agency (2017).

Esch, T., Heldens, W., Hirne, A., Keil, M., Marconcini, M., Roth, A., ... Strano, E. (2017). Breaking new ground in mapping human settlements from space -The Global Urban Footprint-. ISPRS Journal of Photogrammetry and Remote Sensing, 134, 30-42. https://doi.org/10.1016/j.isprsjprs.2017.10.012

Georgescu, M., Chow, W. T. L., Wang, Z. H., Brazel, a, Trapido-Lurie, B., Roth, M., \& Benson-Lira, V. (2015). Prioritizing urban sustainability solutions: coordinated approaches must incorporate scale-dependent built environment induced effects. Environmental Research Letters, 10(6), 061001. https://doi.org/10.1088/1748-9326/10/6/061001

Gorelick, N., Hancher, M., Dixon, M., Ilyushchenko, S., Thau, D., \& Moore, R. (2017). Google Earth Engine: Planetary-scale geospatial analysis for everyone. Remote Sensing of Environment, 202, 18-27. https://doi.org/10.1016/j.rse.2017.06.031

Gong, P., Li, X., Wang, J., Bai, Y., Chen, B., Hu, T., ... Zhou, Y. (2020). Annual maps of global artificial impervious area (GAIA) between 1985 and 2018. Remote Sensing of Environment, 236(October 2019), 111510. https://doi.org/10.1016/j.rse.2019.111510

Grimm, N. B., Faeth, S. H., Golubiewski, N. E., Redman, C. L., Wu, J., Bai, X., \& Briggs, J. M. (2008). Global Change and the Ecology of Cities. Science, 319(5864), 756-760. https://doi.org/10.1126/science.1150195

Hsu, F.-C., Baugh, K., Ghosh, T., Zhizhin, M., \& Elvidge, C. (2015). DMSP-OLS Radiance Calibrated Nighttime Lights Time Series with Intercalibration. Remote Sensing, 7(2), 1855-1876. https://doi.org/10.3390/rs70201855

Kennedy, R. E., Yang, Z., Cohen, W. B., Pfaff, E., Braaten, J., \& Nelson, P. (2012). Spatial and temporal patterns of forest disturbance and regrowth within the area of the Northwest Forest Plan. Remote Sensing of Environment, 122, 117-133. https://doi.org/10.1016/j.rse.2011.09.024

Kennedy, R. E., Yang, Z., Gorelick, N., Braaten, J., Cavalcante, L., Cohen, W. B., \& Healey, S. (2018). Implementation of the LandTrendr algorithm on Google Earth Engine. Remote Sensing, 10(5), 1-10. https://doi.org/10.3390/rs10050691

Ko, B., Kim, H., \& Nam, J. (2015). Classification of Potential Water Bodies Using Landsat 8 OLI and a Combination of Two Boosted Random Forest Classifiers. Sensors, 15(6), 13763-13777. https://doi.org/10.3390/s150613763 
Lemoine-Rodríguez, R., Inostroza, L., \& Zepp, H. (2020). The global homogenization of urban form. An assessment of 194 cities across time. Landscape and Urban Planning, 204(April), 103949. https://doi.org/10.1016/j.landurbplan.2020.103949

Li, H., Wang, C., Zhong, C., Su, A., Xiong, C., Wang, J., \& Liu, J. (2017). Mapping urban bare land automatically from Landsat imagery with a simple index. Remote Sensing, 9(3). https://doi.org/10.3390/rs9030249

Mancino, G., Ferrara, A., Padula, A., \& Nolè, A. (2020). Cross-Comparison between Landsat 8 (OLI) and Landsat $7(\mathrm{ETM}+)$ Derived Vegetation Indices in a Mediterranean Environment. Remote Sensing, 12(2), 291. https://doi.org/10.3390/rs12020291

Pesaresi, M., Huadong, G., Blaes, X., Ehrlich, D., Ferri, S., Gueguen, L., ... Zanchetta, L. (2013). A global human settlement layer from optical HR/VHR RS data: Concept and first results. IEEE Journal of Selected Topics in Applied Earth Observations and Remote Sensing, 6(5), 2102-2131. https://doi.org/10.1109/JSTARS.2013.2271445

Reba, M., \& Seto, K. C. (2020). A systematic review and assessment of algorithms to detect, characterize, and monitor urban land change. Remote Sensing of Environment, 242(May 2019), 111739. https://doi.org/10.1016/j.rse.2020.111739

Schiavina M., Moreno-Monroy A., Maffenini L., Veneri P. (2019). GHSL-OECD Functional Urban Areas 2019, EUR 30001 EN, Publications Office of the European Union, Luxembourg, 2019, ISBN 978-92-76-11258-7, https://doi.org/10.2760/67415, JRC 118845

Stewart, I. D., \& Oke, T. R. (2012). Local Climate Zones for Urban Temperature Studies. Bulletin of the American Meteorological Society, 93(12), 1879-1900. https://doi.org/10.1175/BAMS-D-11-00019.1

Vandamme, S., Demuzere, M., Verdonck, M., Zhang, Z., \& Coillie, F. Van. (2019). Revealing Kunming's (China) Historical Urban Planning Policies Through Local Climate Zones. Remote Sensing, 11(14), 1731. https://doi.org/10.3390/rs11141731

Verdonck, M., Demuzere, M., Bechtel, B., Beck, C., Brousse, O., Droste, A., ... Van Coillie, F. (2019). The Human Influence Experiment (Part 2): Guidelines for Improved Mapping of Local Climate Zones Using a Supervised Classification. Urban Science, 3(1), 27. https://doi.org/10.3390/urbansci3010027

Wang, R., Cai, M., Ren, C., Bechtel, B., Xu, Y., \& Ng, E. (2019). Detecting multi-temporal land cover change and land surface temperature in Pearl River Delta by adopting local climate zone. Urban Climate, 28(June 2018), 100455. https://doi.org/10.1016/j.uclim.2019.100455 
Zhang, H., Chen, Y., \& Zhou, J. (2015). Assessing the long-term impact of urbanization on run-off using a remote-sensing-supported hydrological model. International Journal of Remote Sensing, 1161(October), 1-17. https://doi.org/10.1080/01431161.2015.1094834 


\section{Supplementary Information}
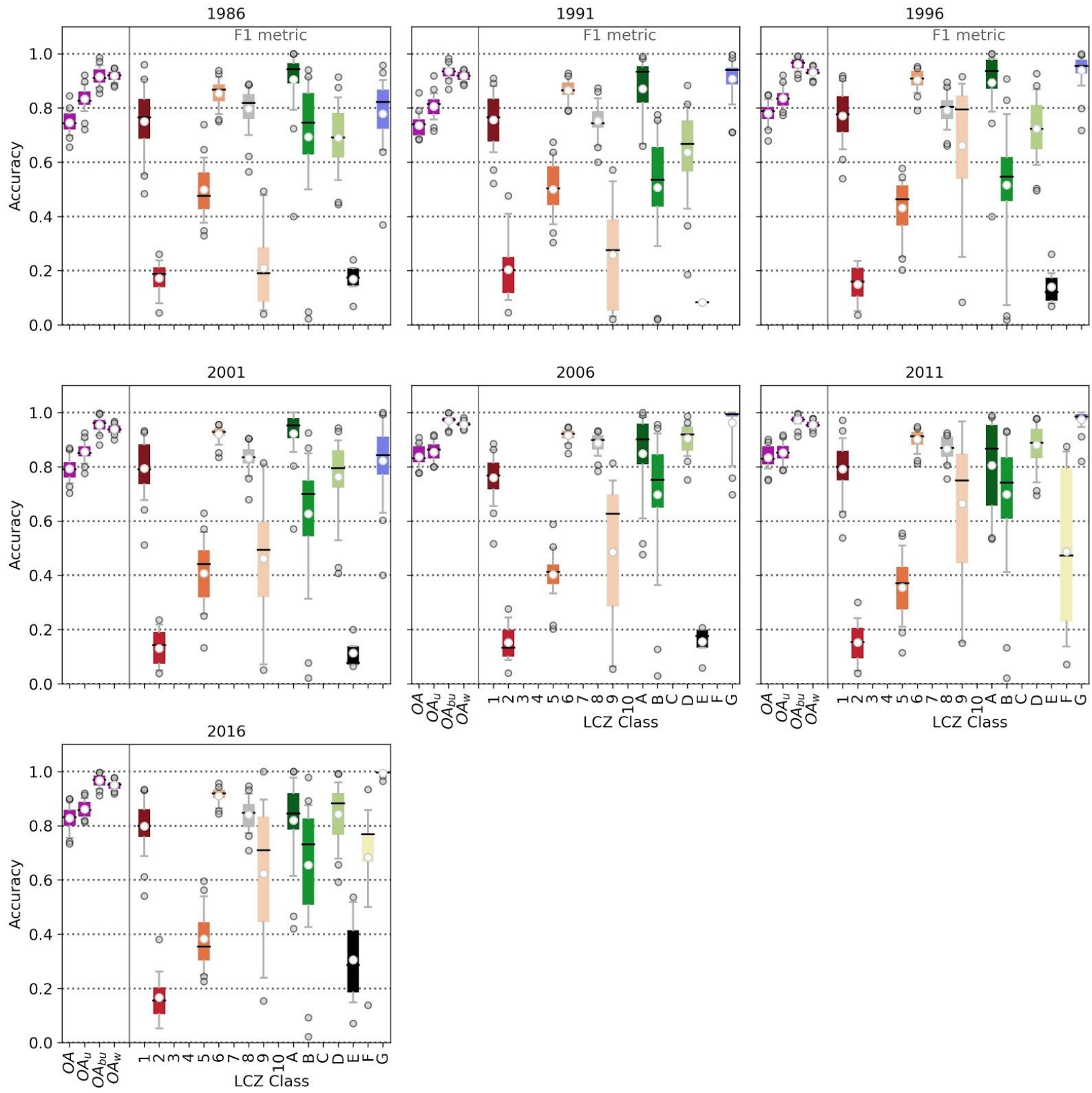

Fig. S1: As Figure 3, but for Calgary. 

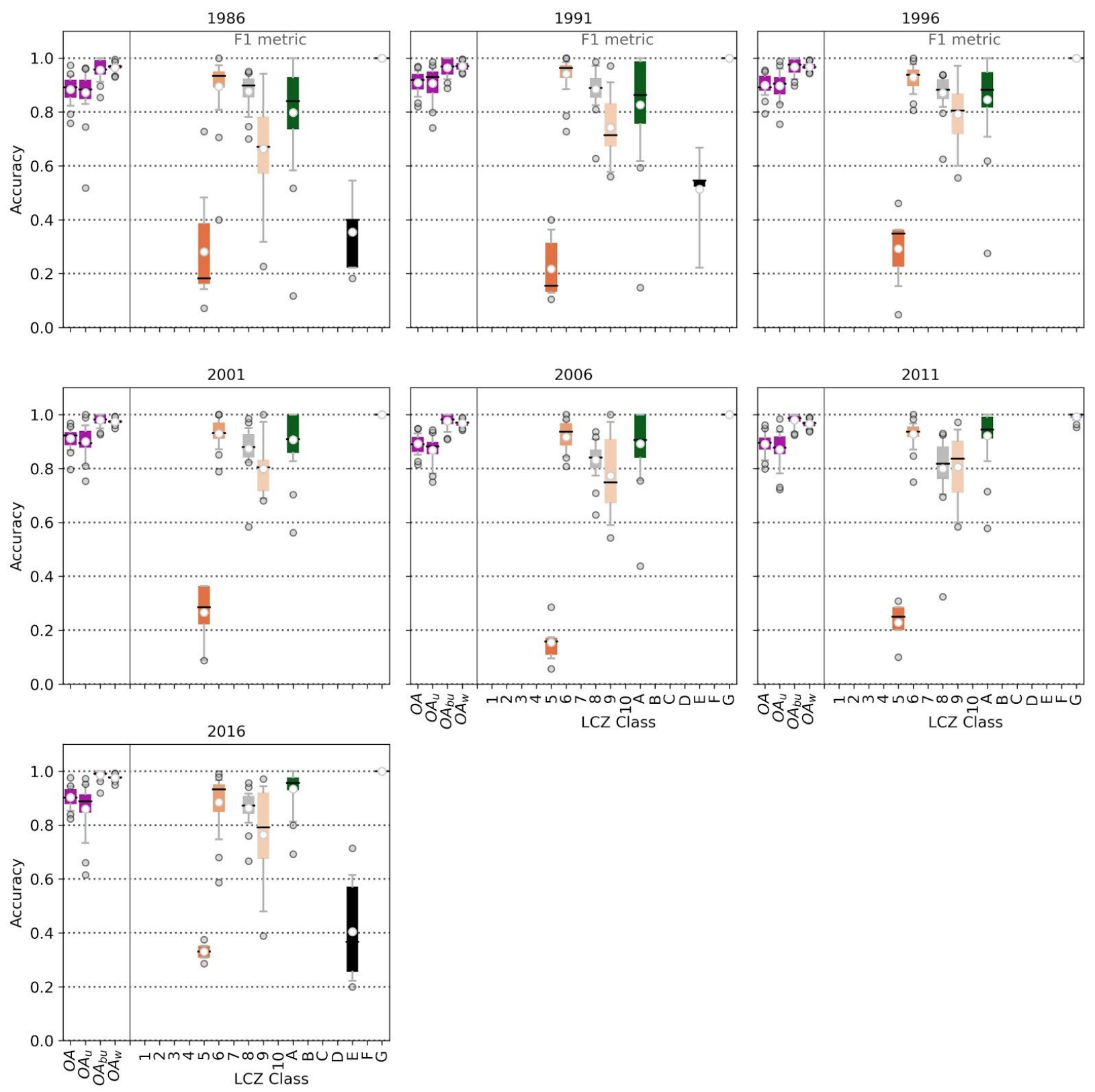

Fig. S2: As Figure 3, but for Halifax. 

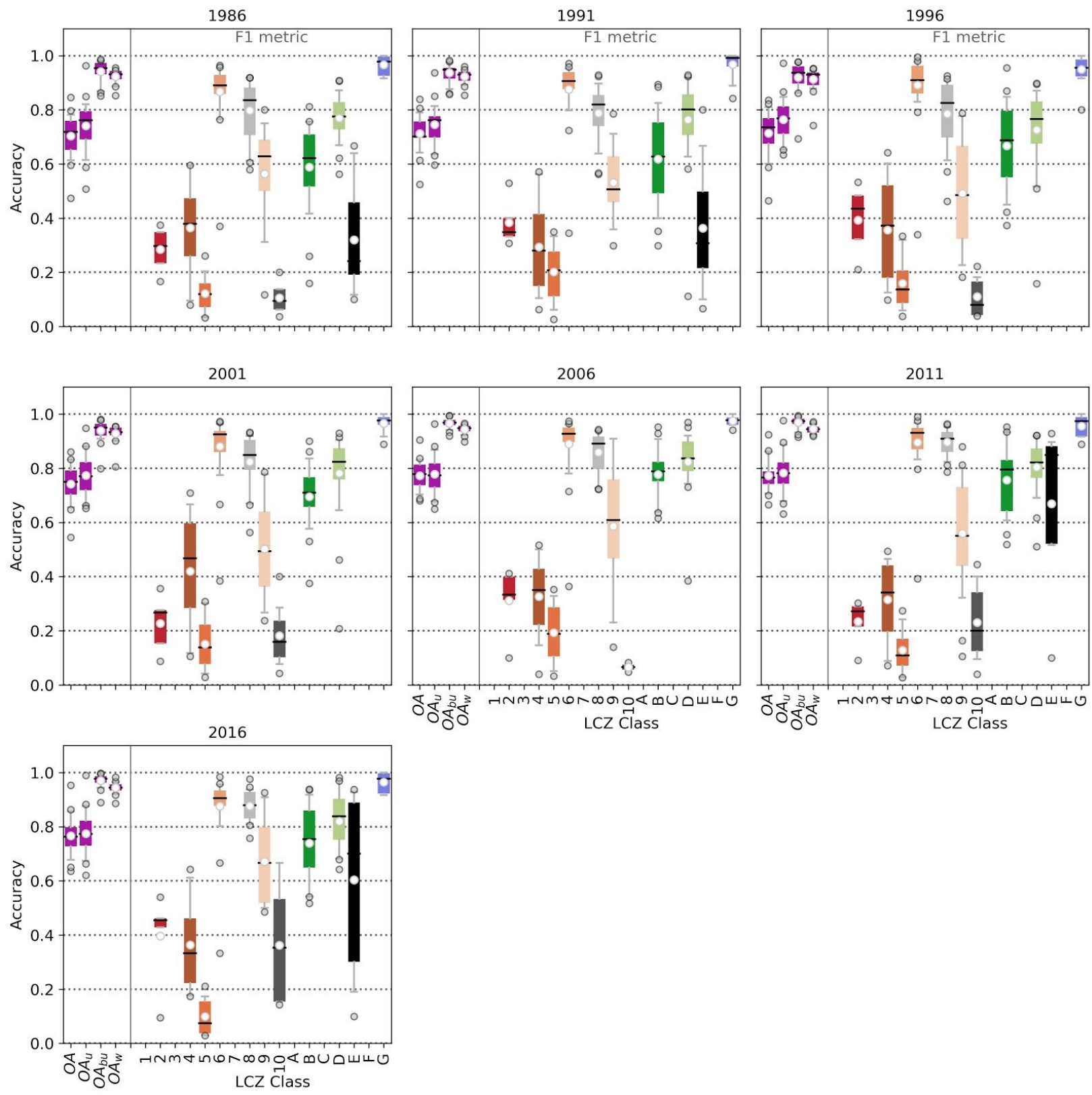

Fig. S3: As Figure 3, but for Edmonton. 

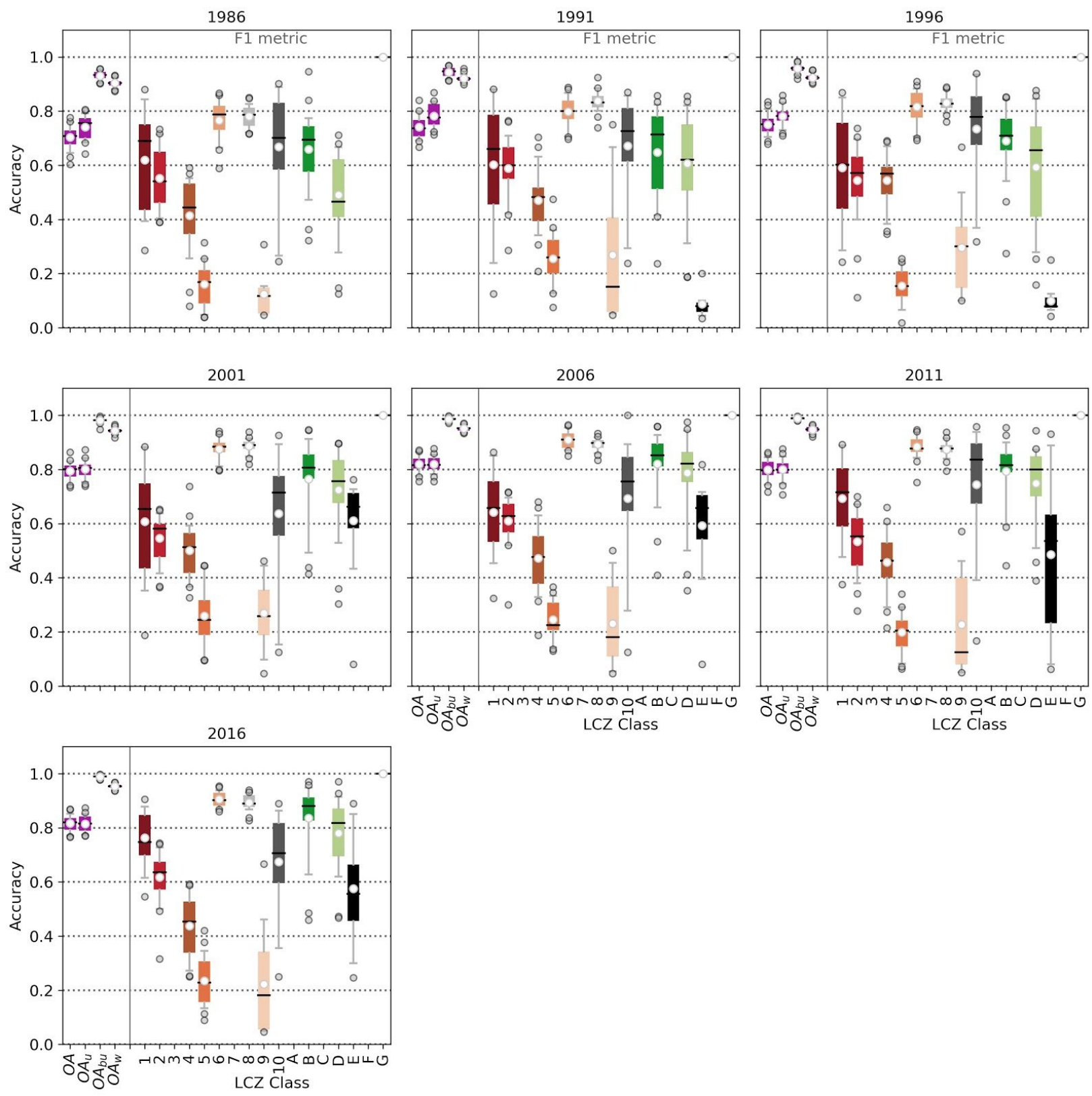

Fig. S4: As Figure 3, but for Toronto. 

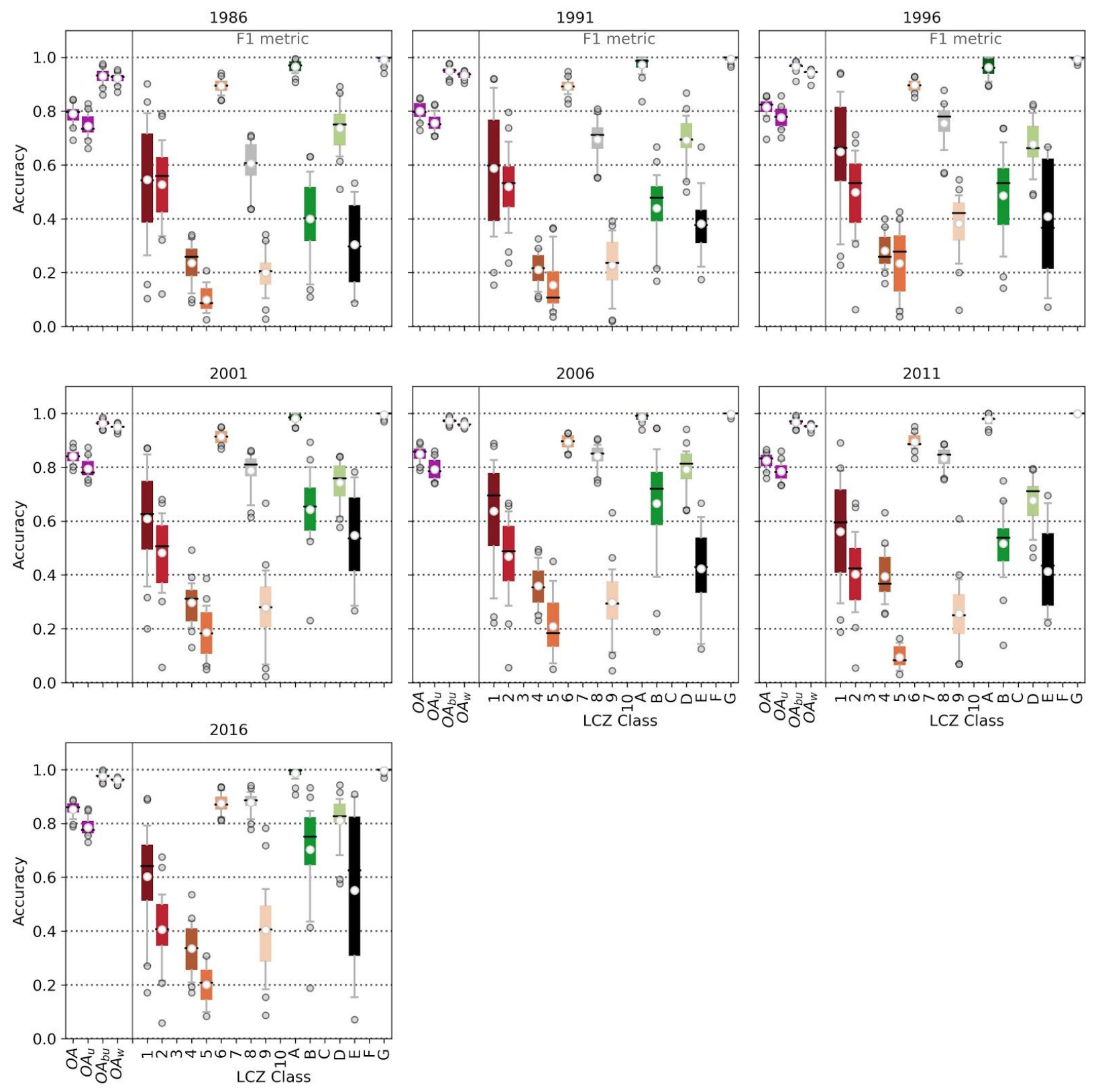

Fig. S5: As Figure 3, but for Vancouver. 

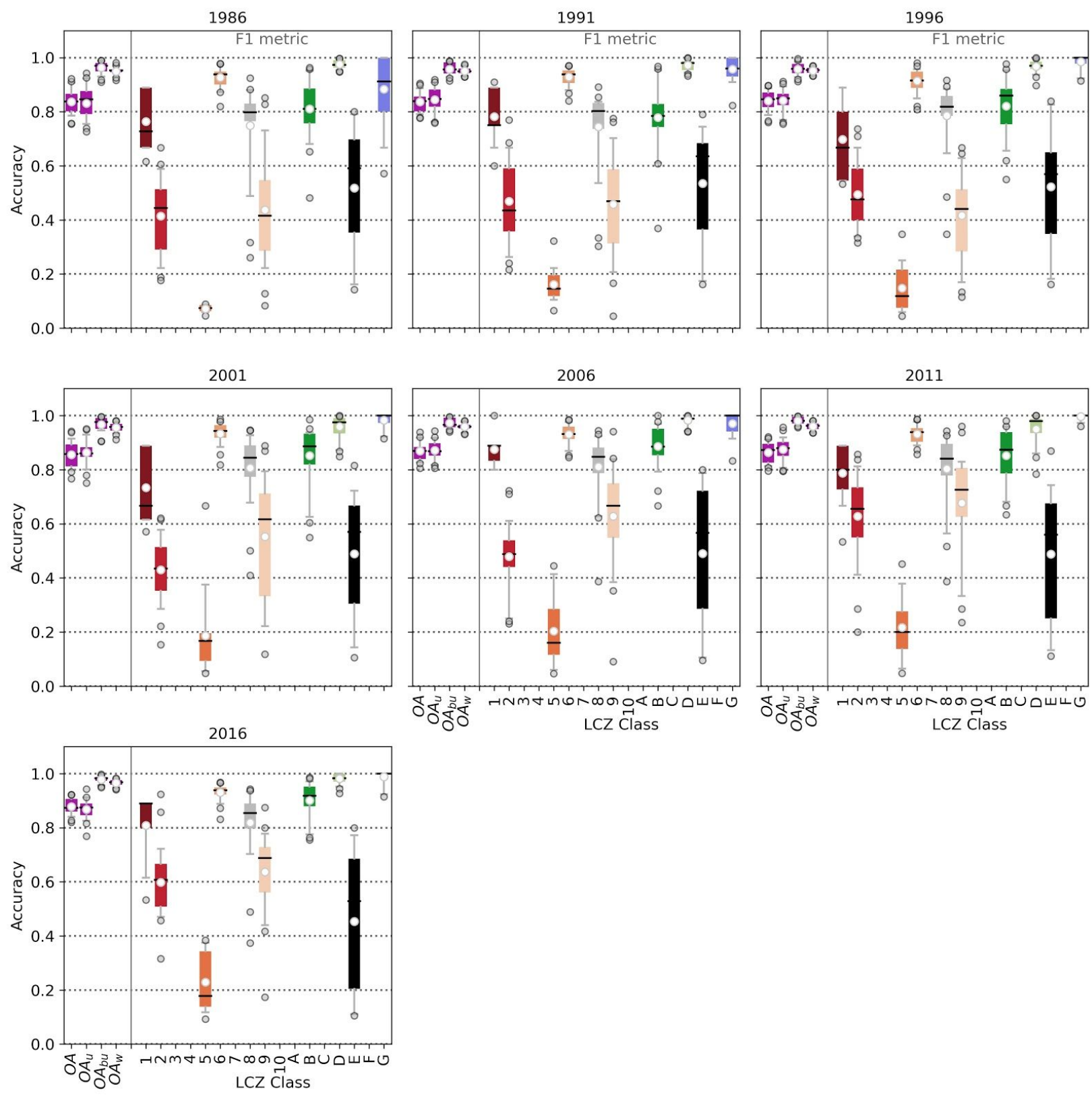

Fig. S6: As Figure 3, but for Winnipeg. 

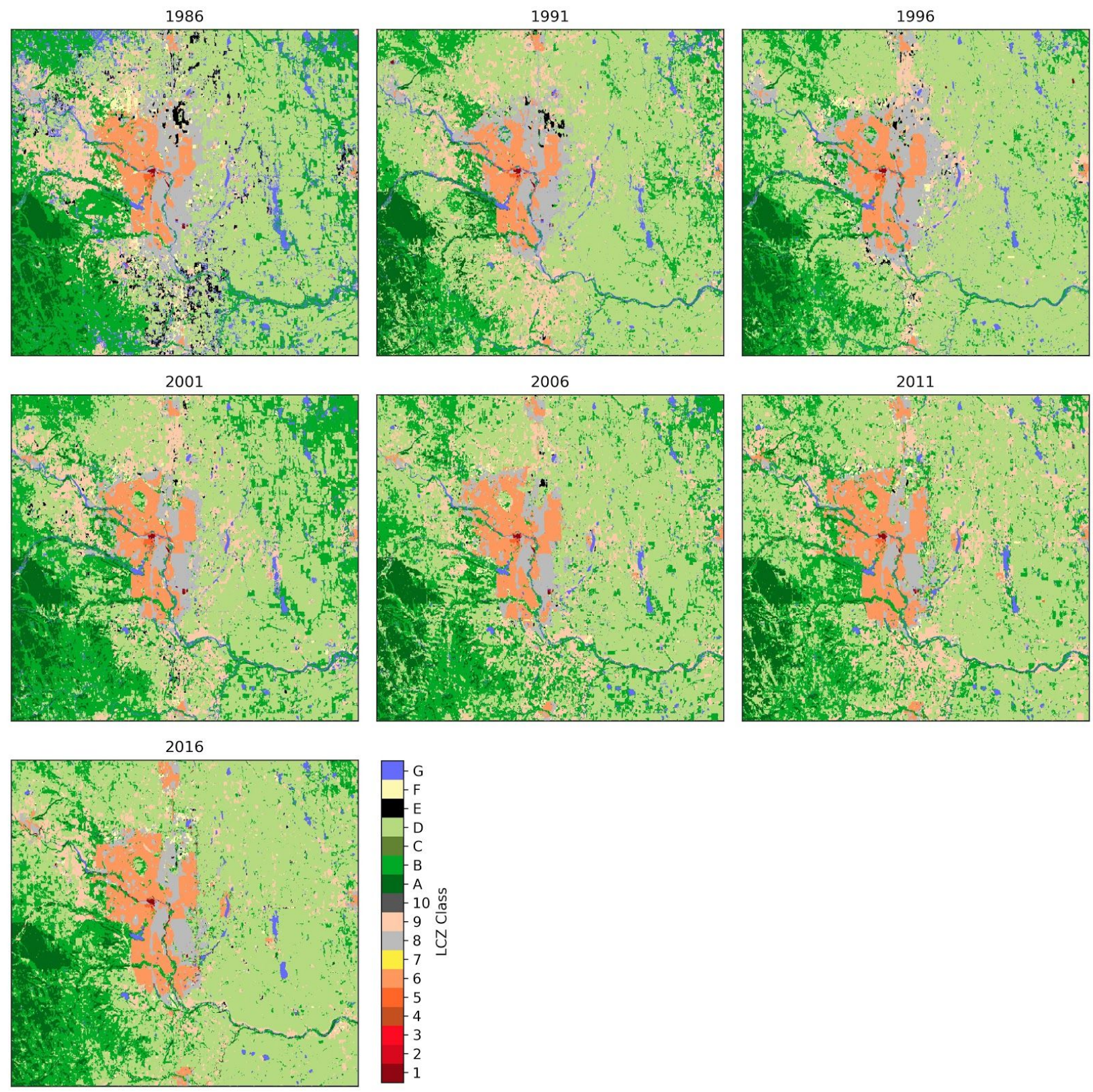

Fig. S7: As Figure 4, but for Calgary. 
1986

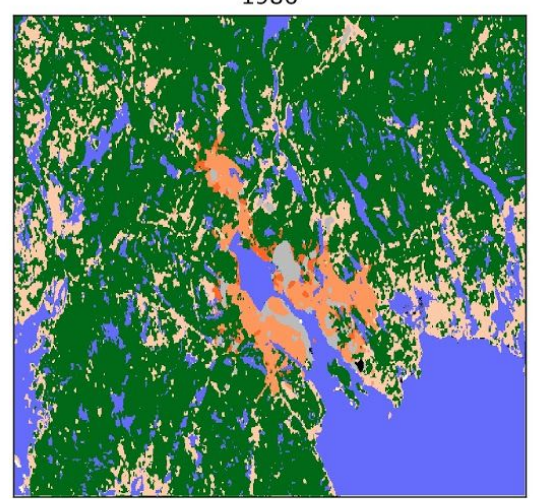

2001

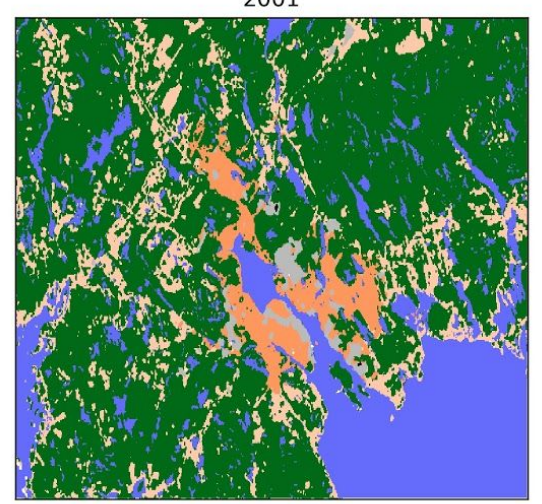

2016

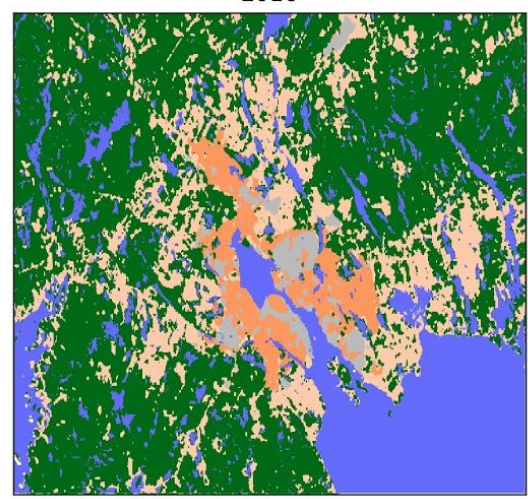

1991

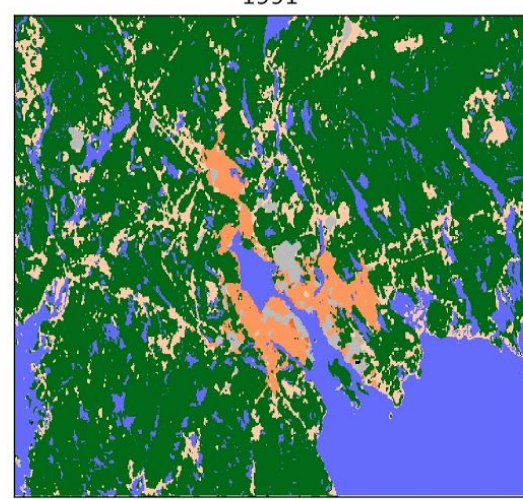

2006

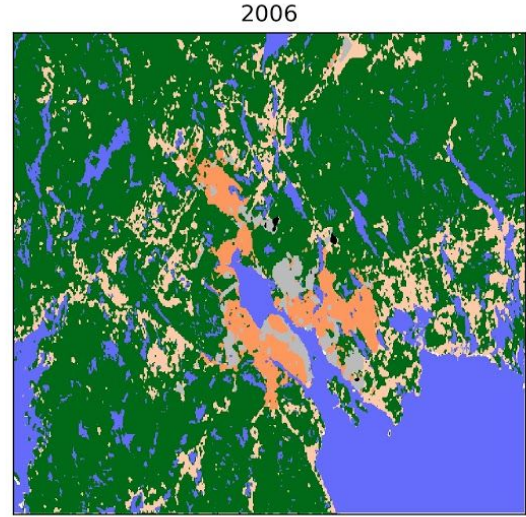

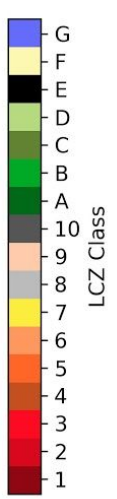
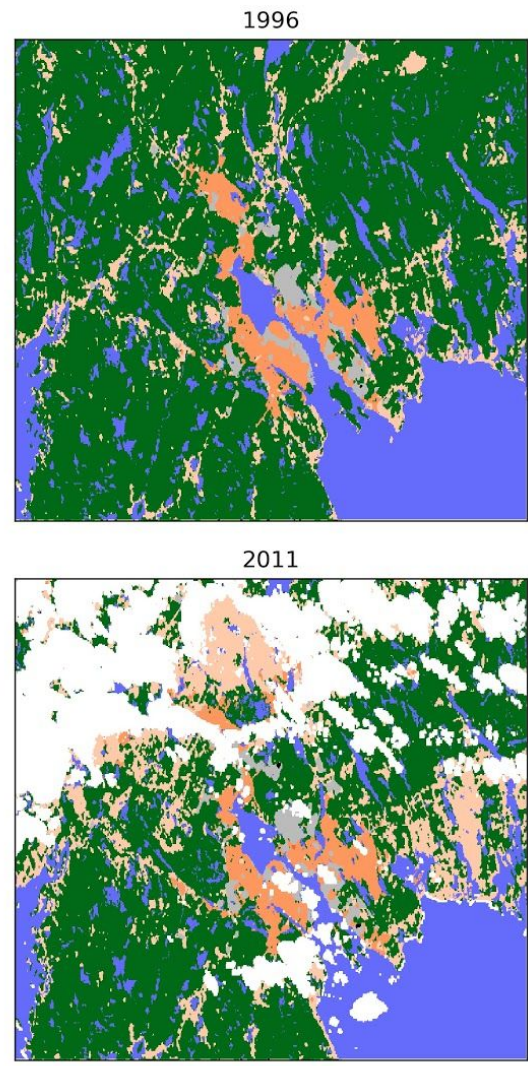

Fig. S8: As Figure 4, but for Halifax. Note that the white areas in the 2011 panel have no data because of cloud cover. 

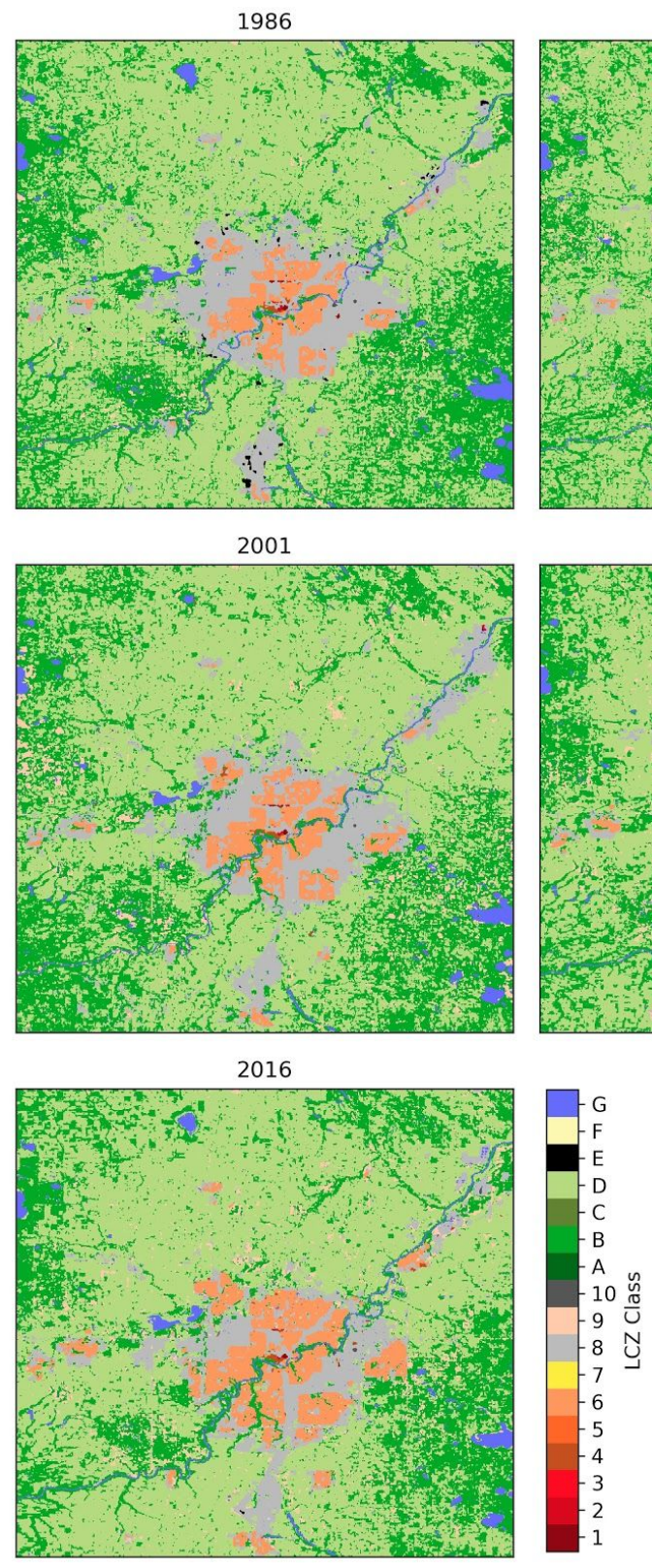

Fig. S9: As Figure 4, but for Edmonton.
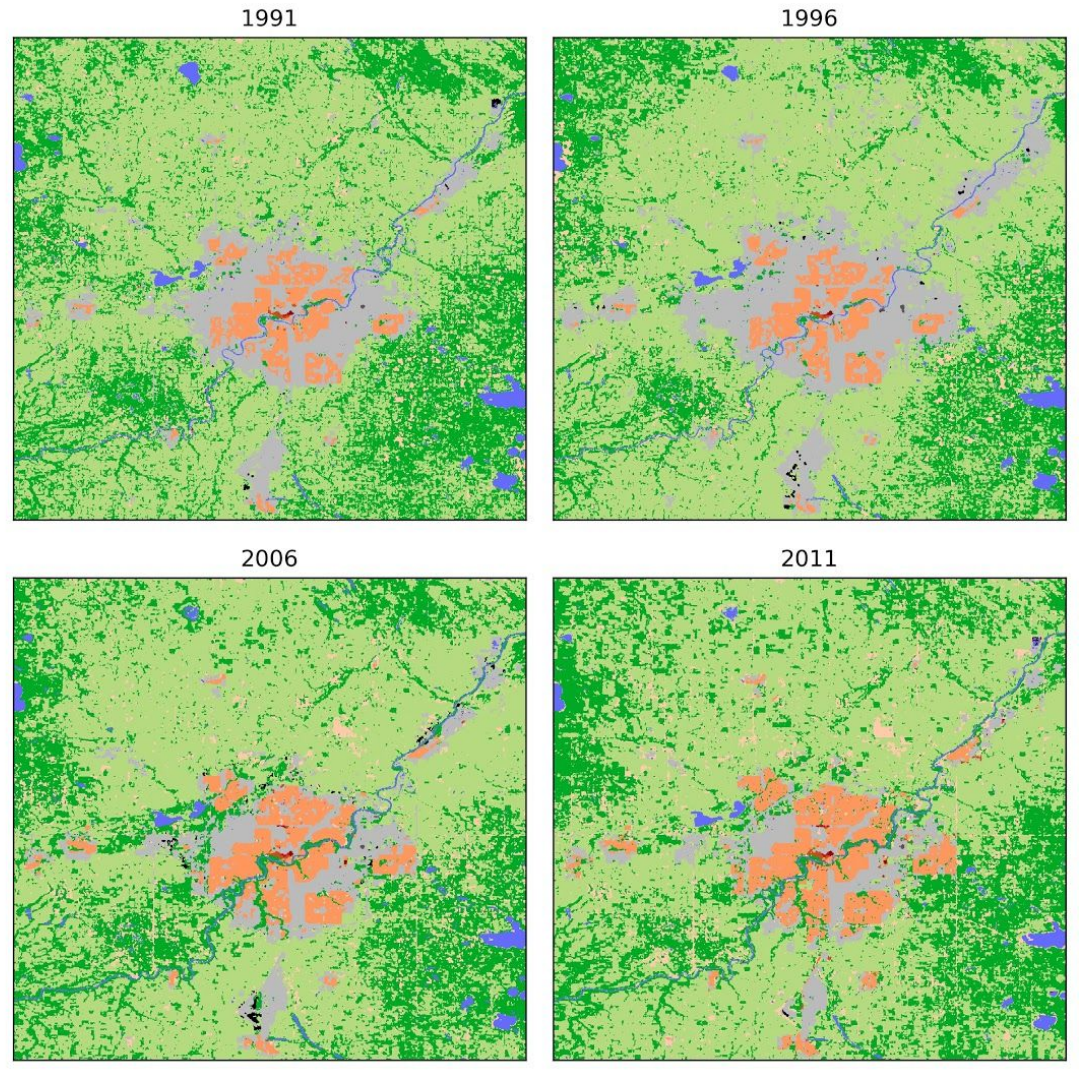

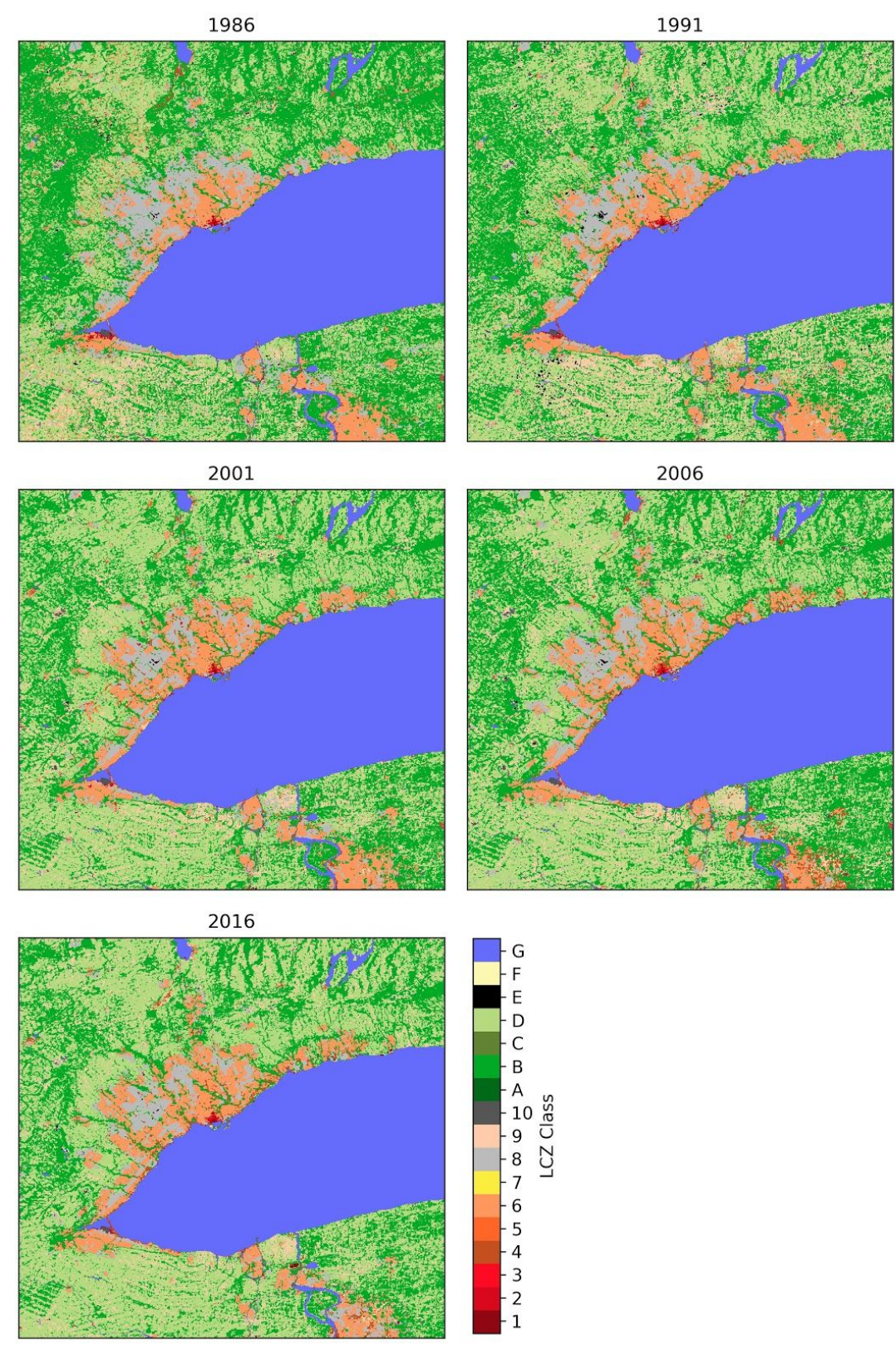
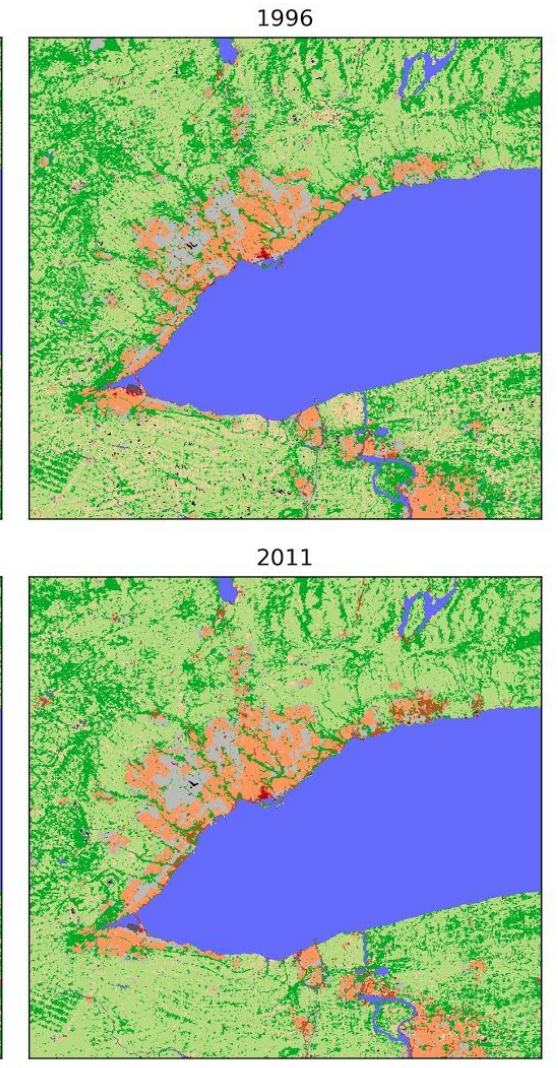

Fig. S10: As Figure 4, but for Toronto. 
1986

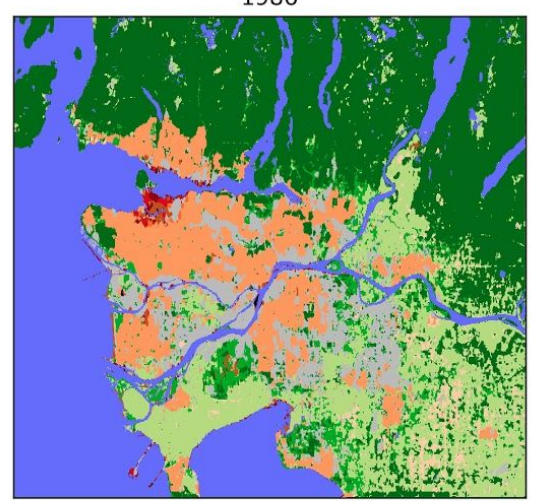

2001

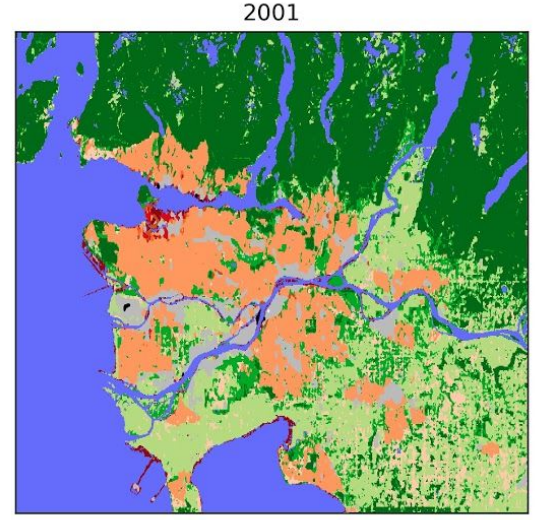

2016
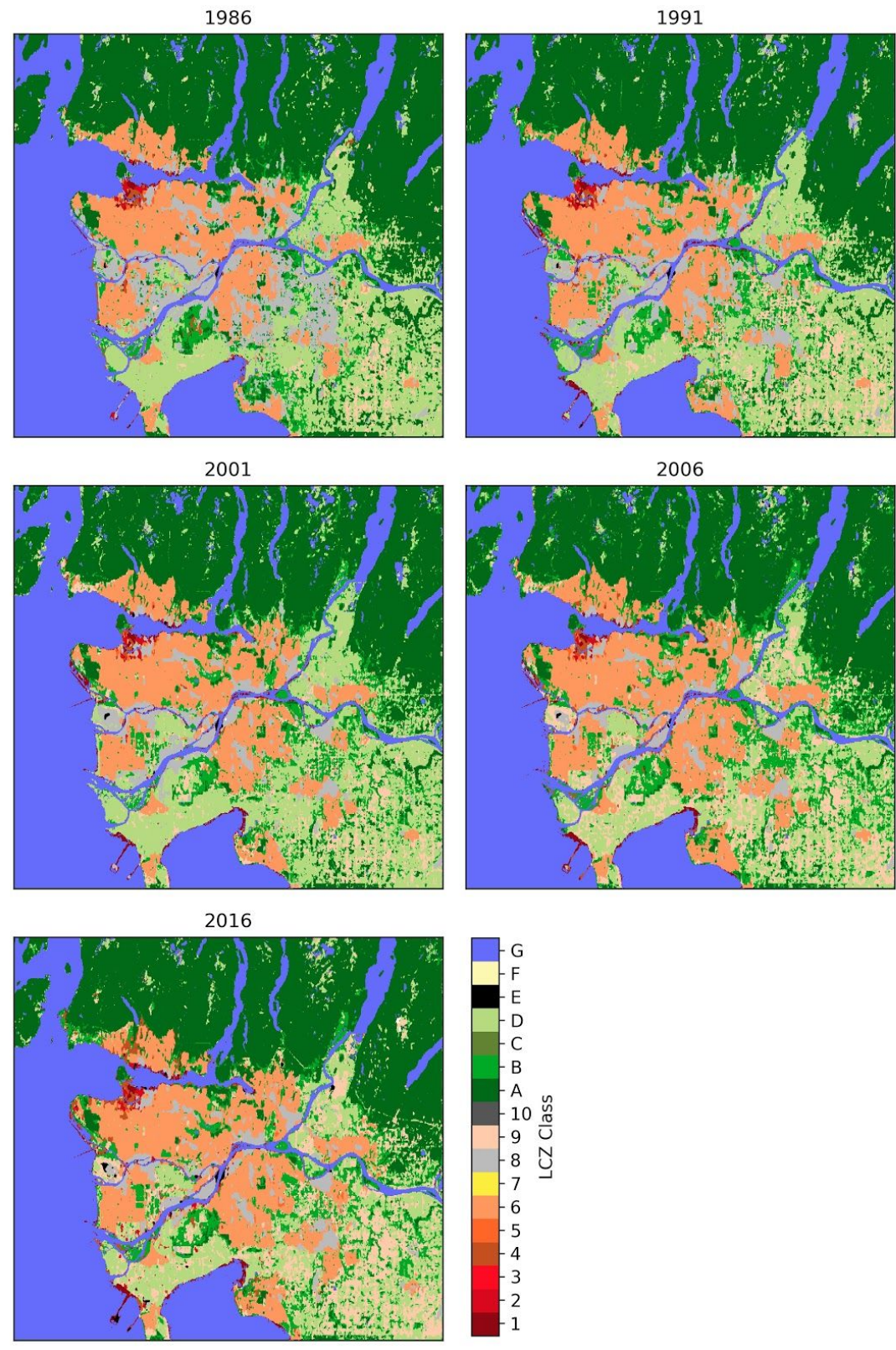

2006

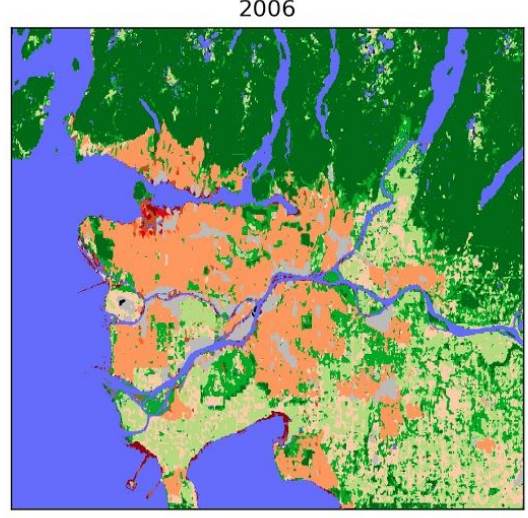

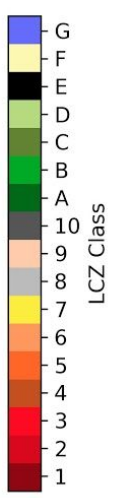

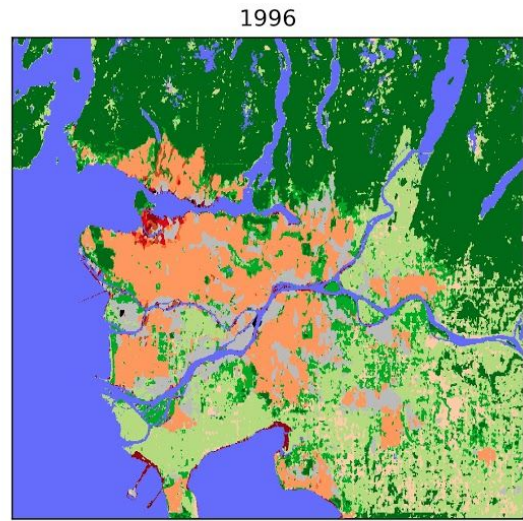

2011

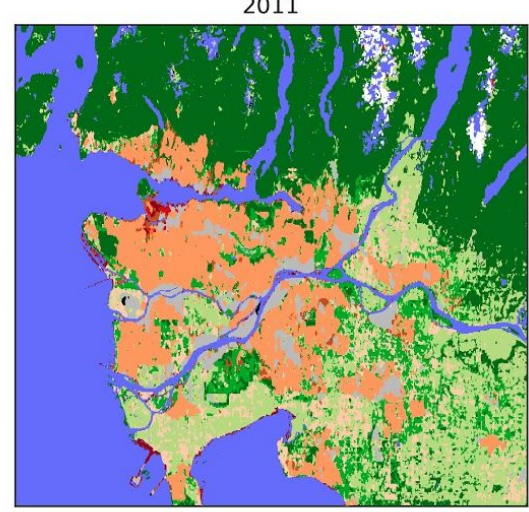

Fig. S11: As Figure 4, but for Vancouver. Note that the white areas in the 2011 panel have no data because of cloud cover. 

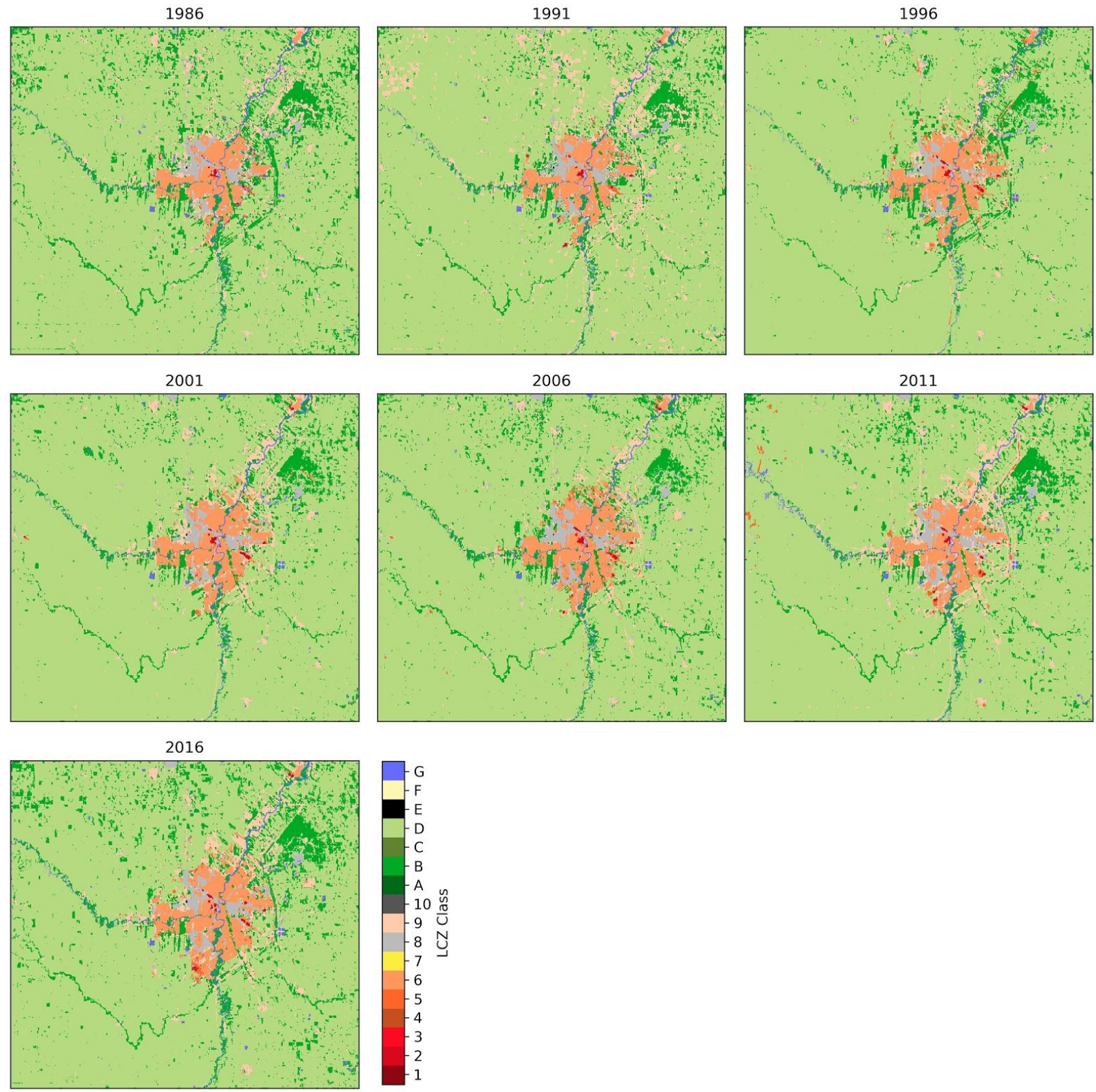

Fig. S12: As Figure 4, but for Winnipeg. 

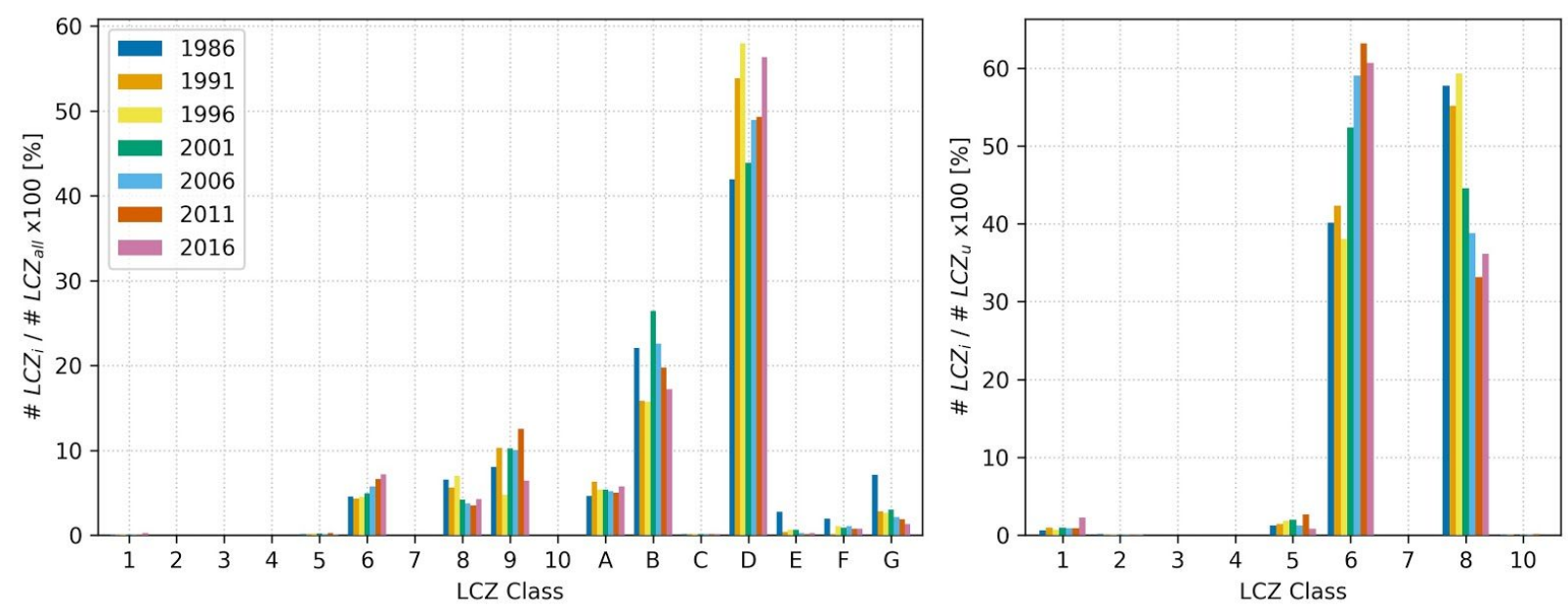

Fig. S13: As Figure 5, but for Calgary.
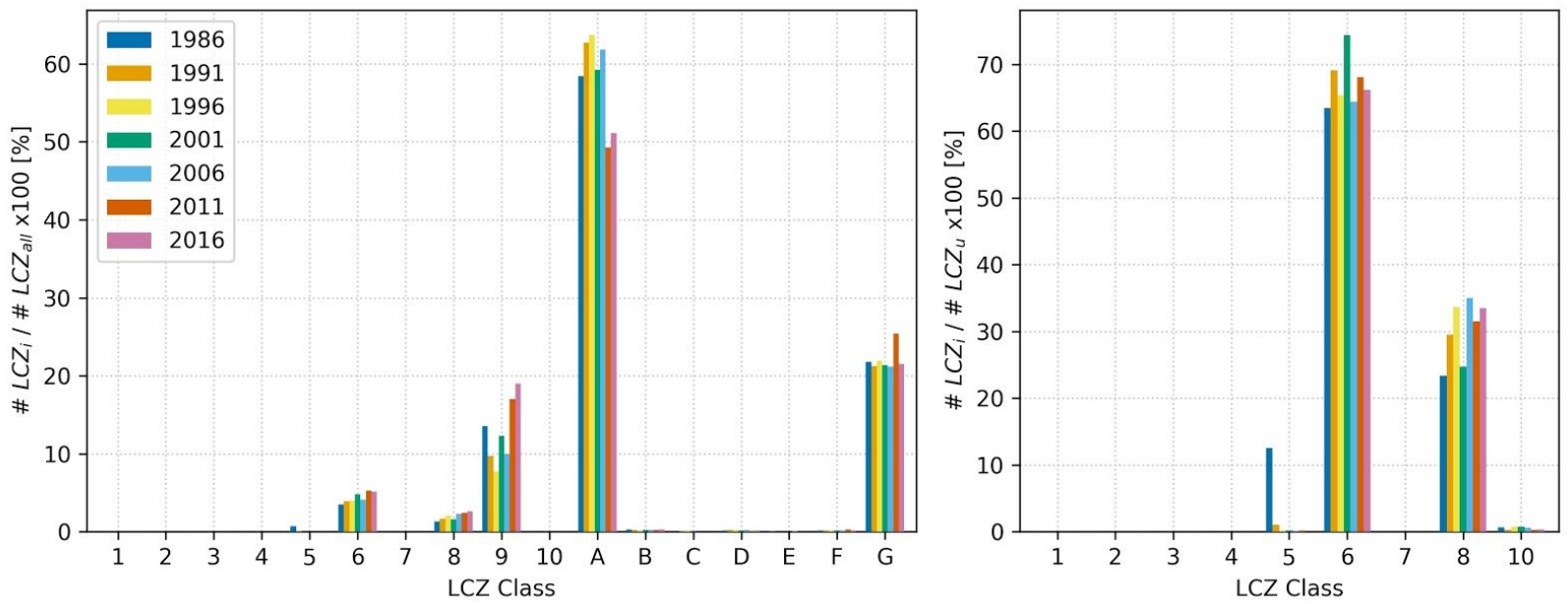

Fig. S14: As Figure 5, but for Halifax. 

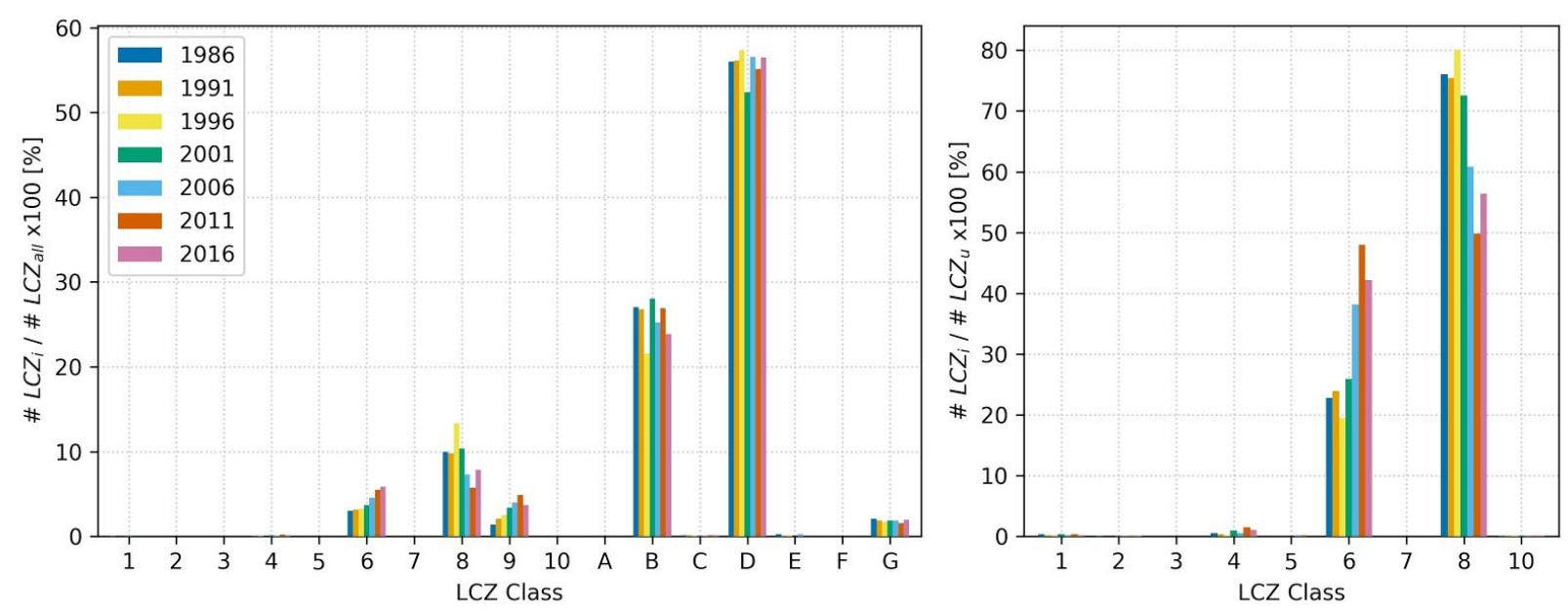

Fig. S15: As Figure 5, but for Edmonton.
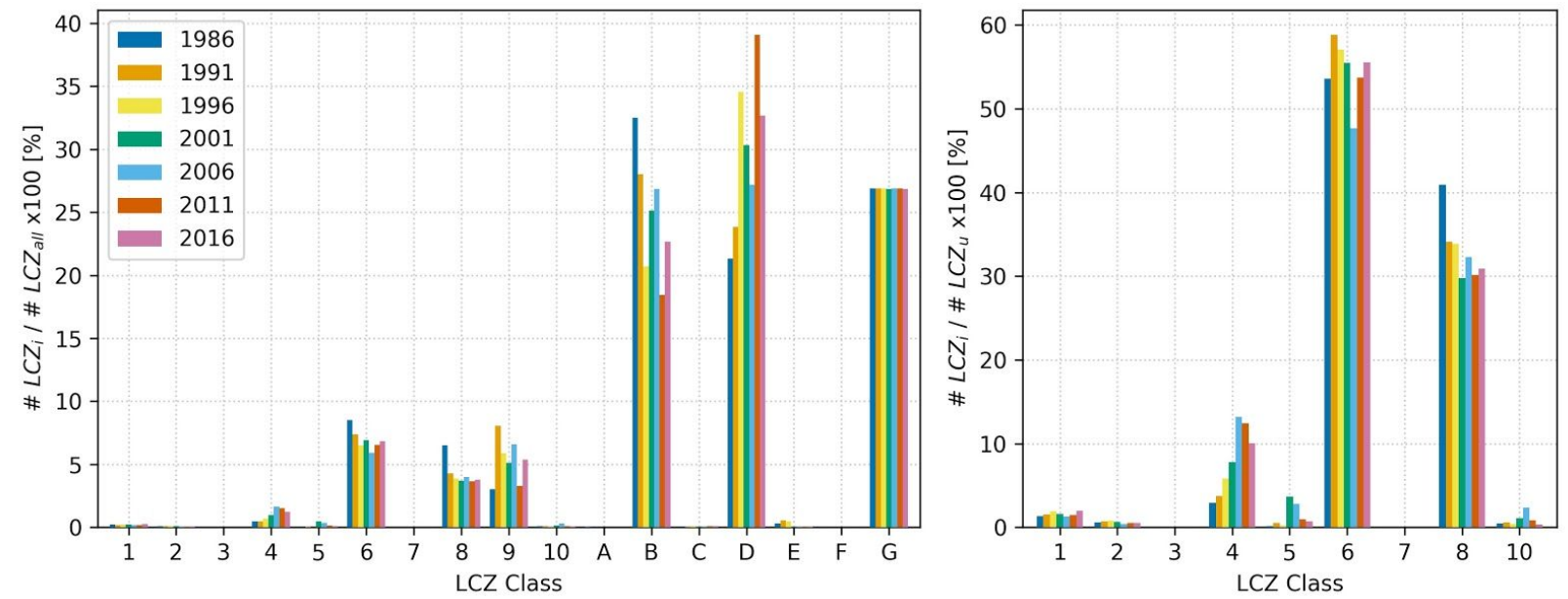

Fig. S16: As Figure 5, but for Toronto. 

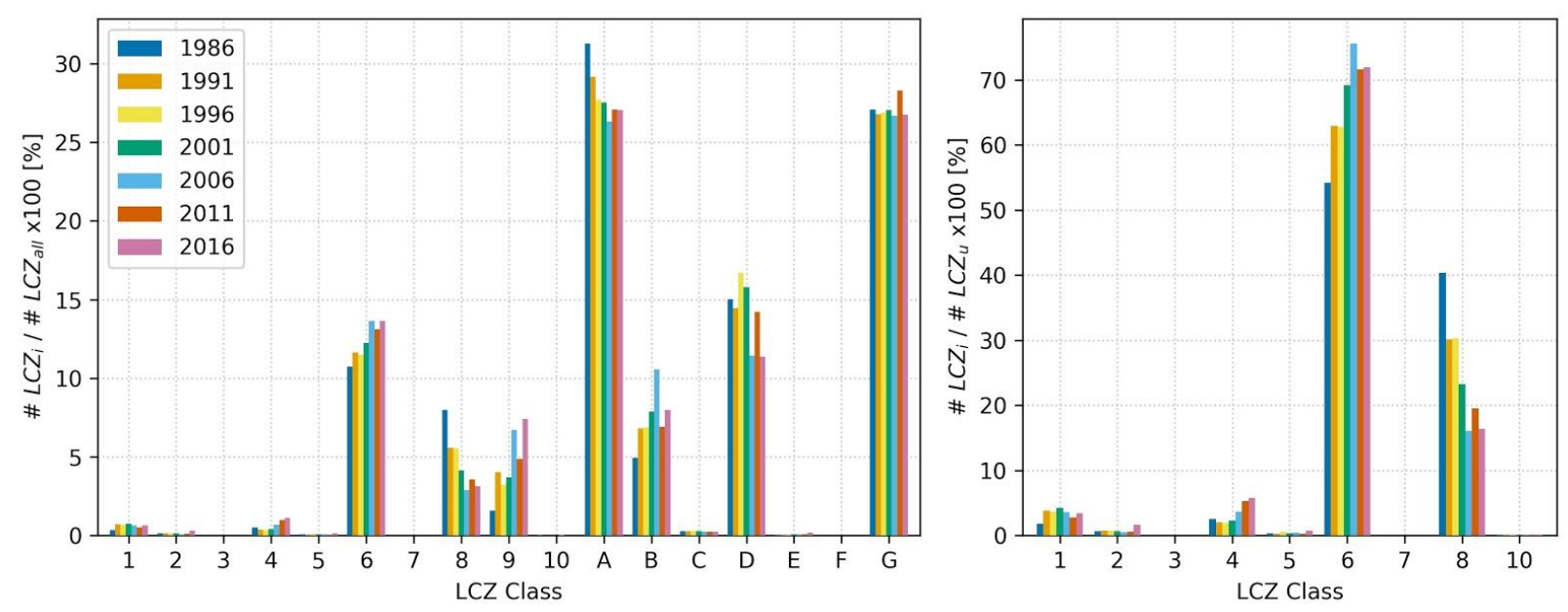

Fig. S17: As Figure 5, but for Vancouver.
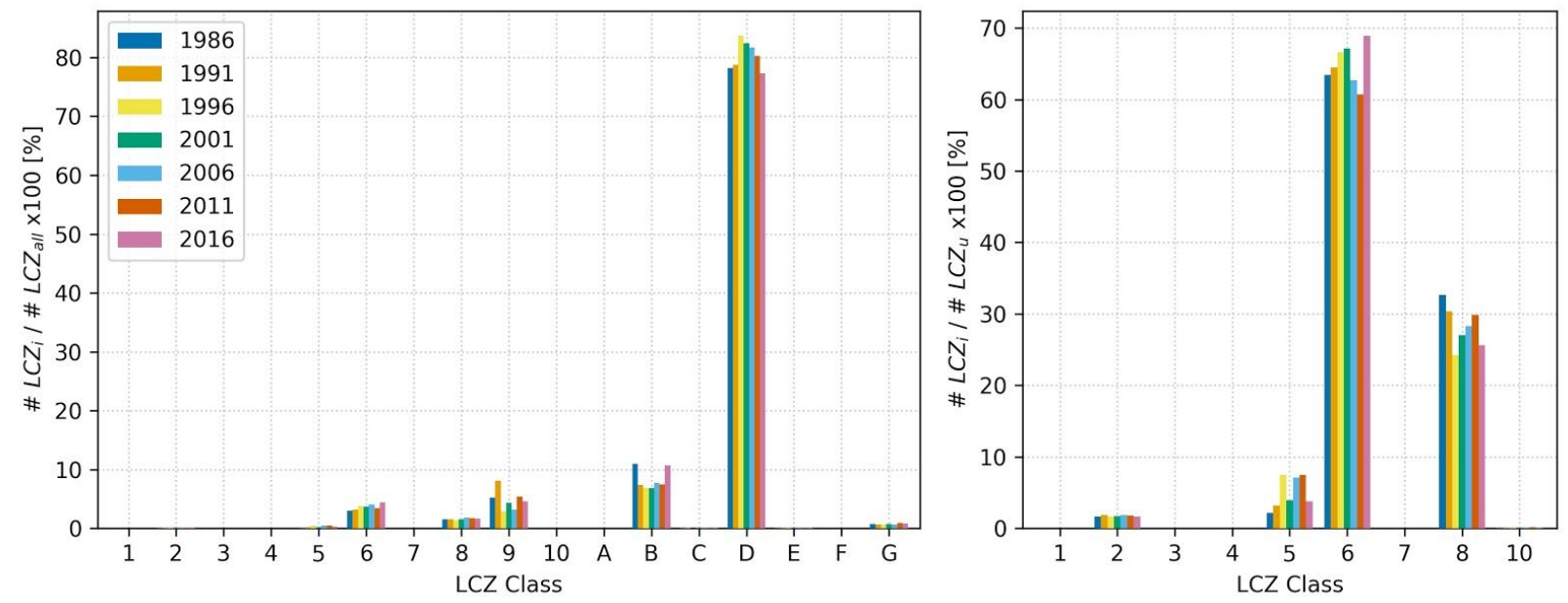

Fig. S18: As Figure 5, but for Winnipeg. 